\title{
Hierarchy of climate and hydrological uncertainties in transient low-flow projections
}

\author{
Jean-Philippe Vidal ${ }^{1}$, Benoît Hingray ${ }^{2,3}$, Claire Magand ${ }^{4,5}$ Eric Sauquet $^{1}$, and Agnès Ducharne ${ }^{4}$ \\ ${ }^{1}$ Irstea, UR HHLY, Hydrology-Hydraulics Research Unit, Villeurbanne, France \\ ${ }^{2}$ CNRS, LTHE UMR 5564, Grenoble, France \\ ${ }^{3}$ Université Grenoble Alpes, LTHE UMR 5564, Grenoble, France \\ ${ }^{4}$ Sorbonne Universités, UPMC, CNRS, EPHE, UMR 7619 METIS, Paris, France \\ ${ }^{5}$ IPSL, LSCE, UPMC, CNRS, UVSQ, Paris, France
}

Correspondence to: Jean-Philippe Vidal (jean-philippe.vidal@irstea.fr)

Received: 30 October 2015 - Published in Hydrol. Earth Syst. Sci. Discuss.: 4 December 2015

Revised: 16 June 2016 - Accepted: 29 July 2016 - Published: 8 September 2016

\begin{abstract}
This paper proposes a methodology for estimating the transient probability distribution of yearly hydrological variables conditional to an ensemble of projections built from multiple general circulation models (GCMs), multiple statistical downscaling methods (SDMs), and multiple hydrological models (HMs). The methodology is based on the quasi-ergodic analysis of variance (QE-ANOVA) framework that allows quantifying the contributions of the different sources of total uncertainty, by critically taking account of large-scale internal variability stemming from the transient evolution of multiple GCM runs, and of small-scale internal variability derived from multiple realizations of stochastic SDMs. This framework thus allows deriving a hierarchy of climate and hydrological uncertainties, which depends on the time horizon considered. It was initially developed for long-term climate averages and is here extended jointly to (1) yearly anomalies and (2) low-flow variables. It is applied to better understand possible transient futures of both winter and summer low flows for two snow-influenced catchments in the southern French Alps. The analysis takes advantage of a very large data set of transient hydrological projections that combines in a comprehensive way 11 runs from four different GCMs, three SDMs with 10 stochastic realizations each, as well as six diverse HMs. The change signal is a decrease in yearly low flows of around $-20 \%$ in 2065, except for the more elevated catchment in winter where low flows barely decrease. This signal is largely masked by both largeand small-scale internal variability, even in 2065. The time of emergence of the change signal is however detected for low-flow averages over 30-year time slices starting as early as 2020 . The most striking result is that a large part of the total uncertainty - and a higher one than that due to the GCMs
\end{abstract}

- stems from the difference in HM responses. An analysis of the origin of this substantial divergence in HM responses for both catchments and in both seasons suggests that both evapotranspiration and snowpack components of HMs should be carefully checked for their robustness in a changed climate in order to provide reliable outputs for informing water resource adaptation strategies.

\section{Introduction}

Incorporating global change in long-term water resource planning, water management, and water governance is a major issue water managers currently have to face (see e.g. Clarvis et al., 2014; Bréthaut and Hill Clarvis, 2015). Indeed, hydrological impacts of climate change may significantly alter amounts and timing of both the water demand and the water availability. Future water availability, informing water resource adaptation strategies, is usually assessed based on hydrological modelling with forcings from general circulation model (GCM) projections for specific catchments and/or at the national scale (see e.g. Christierson et al., 2012; Chauveau et al., 2013). In this context, a water manager with some degree of awareness in potential climate change impact studies is entitled to ask the following question, particularly relevant for long-term planning: for a given year in the future, what will be the probability of having a low-flow value lower than a given baseline? Note that a very similar question has been recently addressed by Sexton and Harris (2015) on the probability of a seasonal temperature/precipitation average for a given year being lower or higher than a present-day 
baseline. In order to answer the water manager question, one should address four different scientific issues: (1) computing future hydrological changes, (2) generating a transient evolution of those changes, (3) disentangling the hydrological change signal from effects of natural/internal climate variability, and (4) focusing on the lower part of the streamflow distribution. The following paragraphs propose a brief review of how the issues listed above have been tackled in the literature.

The first issue has been largely addressed in the literature over the last decades, through the use of hydrometeorological modelling chains composed of GCMs, downscaling techniques - either regional climate models or statistical downscaling methods (SDMs) - and hydrological models (HMs). Such hydrometeorological chains provide a quantification of the hydrological change signal, as well as an estimate of the uncertainty associated to each level of the modelling chain, provided of course that they include multiple models at each level (Wilby and Dessai, 2010). There is a growing body of literature on the quantification of the contribution of each level of the hydrometeorological chain to the overall modelling uncertainty in hydrological changes (Dobler et al., 2012; Finger et al., 2012; Bosshard et al., 2013; Hagemann et al., 2013; Addor et al., 2014; Lafaysse et al., 2014; Schewe et al., 2014; Giuntoli et al., 2015; Vetter et al., 2015). In most cases, contributions from the different sources of uncertainty are derived through more or less formal analysis of variance (ANOVA) techniques which recently became a common tool in climate studies (Yip et al., 2011; Sansom et al., 2013).

These projections are however historically and still generally derived for specific time slices in the future, and only few studies engaged in deriving transient hydrological projections (Lafaysse et al., 2014; Barria et al., 2015).

The issue of quantifying internal climate variability and its additional contribution to modelling uncertainty has retained much attention from the climate community over the last few years (Hawkins and Sutton, 2009, 2011; Deser et al., 2012). The quantification of global climate variability has been recently propagated downstream the modelling cascade in some hydrological studies (Lafaysse et al., 2014; Seiller and Anctil, 2014; Gelfan et al., 2015; Peel et al., 2015; van Pelt et al., 2015). When internal variability is estimated from the analysis of multiple runs from a GCM in most studies, alternatives have been proposed to circumvent the often low number of available runs which prevent simple robust estimations (see e.g. Peel et al., 2015, for an example alternative approach). Another type of internal variability has moreover been taken into account in a few regional studies: the variability of small-scale meteorological features given a signal from GCMs, estimated from stochastic downscaling methods (either perfect-prog methods or weather generators) (Lafaysse et al., 2014; Fatichi et al., 2015; Peel et al., 2015).

Lastly, the majority of hydrological change studies so far mainly focused on uncertainties in the streamflow regime. Some of them explored changes in the entire flow duration curve (Dobler et al., 2012; Bosshard et al., 2013; Fatichi et al., 2015), but relatively few focused on the lower end of the hydrological spectrum (see e.g. Wilby and Harris, 2006; Giuntoli et al., 2015; Vetter et al., 2015).

The objective of this work is to deliver relevant information on possible futures of low flows for informing water resource adaptation strategies. To this aim, it attempts to answer the water manager's question by addressing all four issues listed above for two specific snow-influenced Alpine catchments with high stakes on water resources. This work takes advantage of a very large data set of transient hydrological projections over the 1980-2065 period, that gathers all possible combinations of hydrometeorological modelling chains built from 11 runs from four different GCMs, three SDMs with 10 stochastic realizations each, as well as six diverse HMs. Time series of mean annual minimum flow over 7 days are first derived separately for winter and summer for both catchments and for each of the 1980 hydrological projections. The quasi-ergodic analysis of variance $(\mathrm{QE}-$ ANOVA) framework developed by Hingray and Saïd (2014) is applied on this low-flow data set to quantify the relative contributions of (1) model uncertainty due to GCMs, SDMs, and HMs, but also critically of (2) both large-scale and localscale components of internal variability. This framework is here extended to analyse not only changes in time-slice averages but also yearly anomalies, in order to take account of the year-to-year variability that is of much interest for operational water management.

Section 2 introduces the two case study catchments and describes the hydrological projection data set used. Section 3 presents the selected low-flow indicator for two separate seasons and details the QE-ANOVA approach and its adaptation and extension to yearly anomalies of low flows. Results are given in Sect. 4 and discussed in Sect. 5.

\section{Data}

\subsection{Case study catchments}

The Durance basin is located in the southern French Alps, and water flows into the Rhône river. This basin has a total area of $14000 \mathrm{~km}^{2}$ and an altitude range of $4000 \mathrm{~m}$. It carries high stakes for water resources, as it produces $10 \%$ of French hydropower and supplies drinking water to approximately 3 million people (Warner, 2013). It is moreover exposed to various climatic influences, from Alpine climate in the upper northern part to Mediterranean climate in the lower southern part. Water resources are already under high pressure due to substantial abstractions within and out of the river basin, and global change will question the sustainability of the current rules for water allocation among the different uses, among all other governance challenges (Bréthaut and Hill Clarvis, 2015). The R2D2-2050 project addressed this issue by building projections of future water availability, prospective sce- 


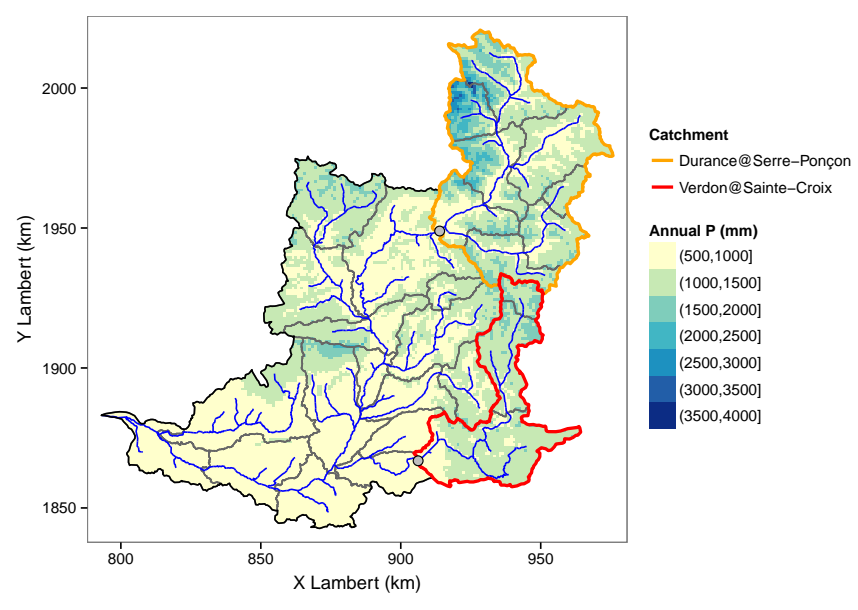

Figure 1. Delineation of the Durance basin and the two case study catchments drawn on the gridded map of the 1980-2009 mean annual precipitation from the SPAZM reanalysis (Gottardi et al., 2012). The coordinate system is the Lambert II Étendu conformal conic projection (http://www.ign.fr/sites/all/files/geodesie_ projections.pdf).

narios of water demand, as well as prospective scenarios of future water management (Sauquet et al., 2014).

Two case study catchments are considered here: the Durance@Serre-Ponçon and the Verdon@Sainte-Croix (see Fig. 1). They have been selected here for two main reasons: first, they are located upstream the two largest reservoirs in the Durance catchment, the Serre-Ponçon reservoir being actually the second largest in Europe. The management of these reservoirs is coordinated to fulfil water demands from various uses. Second, their hydrological regime is largely influenced by snowpack/snowmelt processes, with differences stemming from their altitude range and geographical location. The Durance@Serre-Ponçon $\left(3580 \mathrm{~km}^{2}\right)$ is located in the heart of the French Alps and more than half of its area is above $2500 \mathrm{~m}$. It contains a small glacierized part $(0.5 \%$ of the catchment area, Gardent et al., 2014) that may contribute to late summer streamflow in some specific upper subcatchments (Lafaysse et al., 2011), but much less so for the whole catchment. The Verdon@Sainte-Croix $\left(1620 \mathrm{~km}^{2}\right)$ is located on the southern Mediterranean edge of the Alpine range, with a maximum altitude of $2500 \mathrm{~m}$.

Reconstitutions of natural streamflow for both stations were provided by the EDF power company which manages both Serre-Ponçon and Sainte-Croix reservoirs. Reconstructed streamflow were derived prior to the R2D2-2050 project from outflows and stored volumes in the two reservoirs, and corrected from the influence of other upstream hydropower reservoir operations. In this study, these reconstructed streamflow time series were only used to calibrate some of the HMs as detailed in Sect. 2.2.3.

\subsection{Hydrological projection data set}

\subsubsection{Global climate projections}

Climate projections over the Durance basin are based on global projections from the ENSEMBLES project (van der Linden and Mitchell, 2009) and, more specifically, from the STREAM2 simulations using more recent versions of the GCMs (Johns et al., 2011). The simulations used here are forced by $20 \mathrm{C} 3 \mathrm{M}$ forcings (historical forcing by greenhouse gases and aerosols) until the year 2000, and emissions from the A1B scenario afterwards (Nakićenović et al., 2000). Table 1 lists the GCM runs used in this study, for which appropriate variables for downscaling were available from the ENSEMBLES project website ${ }^{1}$. The specific period considered here runs from 1 August 1958 to 31 July 2065.

\subsubsection{Downscaled climate projections}

The spatial resolution of the global projections is not adapted to hydrological modelling over small areas like the Durance basin. A downscaling step has therefore been performed within a previous project on this basin (RIWER2030, Hingray et al., 2013). Three statistical downscaling methods (SDMs) have been applied here (see Table 2), all of them primarily based on the analogue principle introduced by Lorenz (1969). This principle relies on the assumption that similar large-scale atmospheric circulation patterns lead to similar local-scale values of near-surface meteorological variables. SDMs build statistical relationships between an archive for predictors and an archive for predictands. For each GCM run, each SDM provides 100 stochastic realizations of meteorological time series in order to generate a probabilistic output of the downscaling step (see Lafaysse et al., 2014, for details on the stochastic generation process). All three methods have been extensively used in previous climate change impact studies (see e.g. Bourqui et al., 2011; Vidal et al., 2012; Chauveau et al., 2013; Lafaysse et al., 2014), and their main characteristics are given in Table 2. Further details on the SDMs are given by Hingray et al. (2013, p. 24: with their notations, the versions used here are analog20, d2gen22, and dsclim11), Hingray and Saïd (2014), and Lafaysse et al. (2014).

The archive for predictors is the NCEP/NCAR global reanalysis (Kalnay et al., 1996) and the archive for predictands is the DuO near-surface reanalysis (Magand et al., 2014) built as a hybrid between the SPAZM (Gottardi et al., 2012) and Safran (Vidal et al., 2010) reanalyses. DuO combines the higher spatial resolution of SPAZM $\left(1 \mathrm{~km}^{2}\right)$ - relevant, for example, for high-altitude precipitation - and the higher temporal resolution (hourly) and the additional variables (including wind and radiation) of Safran that are required inputs for land surface models. The period considered as an archive for analogue dates runs from 1 August 1980 to 31 July 2005

\footnotetext{
${ }^{1}$ http://ensembles-eu.metoffice.com
} 
Table 1. Global model runs under the A1B emissions scenario. Different runs from a given GCM correspond to simulations differing only from their initial conditions (see Johns et al., 2011)

\begin{tabular}{lllll}
\hline Acronym & Institute & GCM name & $\begin{array}{l}\text { Number } \\
\text { of runs }\end{array}$ & Reference \\
\hline CNCM33 & CNRM (France) & CNRM-CM3.3 & 1 & Salas-Mélia et al. (2005) \\
EGMAM2 & FUB (Germany) & EGMAM+ & 1 & Huebener et al. (2007) \\
IPCM4 & IPSL (France) & IPSL-CM4_v2 & 3 & Marti et al. (2010) \\
ECHAM5 & DMI (Denmark) \& MPI (Germany) & ECHAM5-C & 6 & Roeckner et al. (2006) \\
\hline
\end{tabular}

Table 2. Statistical downscaling methods.

\begin{tabular}{lllll}
\hline Acronym & Institute & Method name & Description & Reference \\
\hline analog & EDF/LTHE & analog20 & Analogues & Obled et al. (2002) \\
dsclim & CERFACS & dsclim11a2 & Weather types + transfer functions & Boé et al. (2006) \\
d2gen & LTHE & d2gen22 & Transfer functions + analogues & Mezghani and Hingray (2009) \\
\hline
\end{tabular}

(Hingray et al., 2013). Local-scale variables for target dates are taken as the ones from each analogue date. The PenmanMonteith reference evapotranspiration (ET0, Allen et al., 1998) required as an input by conceptual models is additionally computed from meteorological variables. An additional correction on the temperature of the analogue date is moreover potentially applied to ensure the consistency with largescale regional temperature from the GCM (Mezghani and Hingray, 2009; Boé et al., 2009; Hingray et al., 2013). When such a correction is applied, related meteorological variables like infrared radiation or specific humidity from the analogue date are also corrected for ensuring intervariable consistency following Etchevers et al. (2002).

The downscaling process thus led to 3300 (11 GCM runs $\times 3$ SDMs $\times 100$ realizations) hourly/daily gridded climate projections over the Durance catchment for the period from 1 August 1958 to 31 July 2065. A subsampling of 10 realizations out of 100 from each combination of SDM and GCM runs has next been applied to reduce the number of different forcings for the impact models and therefore lighten the computational burden by an order of magnitude. This subsampling was made through a Latin hypercube sampling (LHS) approach, which allows to subsample a multidimensional distribution while preserving its marginal properties (McKay et al., 1979; Minasny and McBratney, 2006). This approach has been recently used by Christierson et al. (2012) and Green and Weatherhead (2014) to sample the UKCP09 probabilistic climate projections (Murphy et al., 2009). The conditioning variables used for the LHS have been carefully chosen based on their relevance for water resource management: they are changes - between 1980-2009 and 20352065 at the scale of the whole Durance basin - of summer and winter precipitation and temperature, and of interannual variability of annual precipitation and temperature.

\subsubsection{Hydrological projections}

Six HMs have been run by different R2D2-2050 project partners over up to 26 catchments in the Durance basin during the project. Only simulations with GCM-driven forcings described above at the two selected catchments described in Sect. 2.1 are considered in the present work. The main characteristics of the six models as well as the calibration approaches against the reference period 1980-2009 - called REF in the following - are shown in Table 3. All conceptual models use a degree-day approach for modelling the snowpack evolution, while physically based models rely on their energy balance models (three-layer snow model for CLSM and one-layer model with constant properties for ORCHIDEE). All conceptual models use Penman-Monteith ET0 while physically based ones compute actual evapotranspiration from their water and energy balance models. Most of these models have been extensively used in previous climate change impact and adaptation studies in other French catchments, often in multimodel contexts (see e.g. Paiva et al., 2010; Moatar et al., 2010; Bourqui et al., 2011; Chauveau et al., 2013; Habets et al., 2013).

The hydrological modelling step thus led to 1980 transient hydrological projections - 330 downscaled climate projections multiplied by six HMs - for the period from $1 \mathrm{Au}-$ gust 1958 to 31 July 2065. They include daily streamflow, actual evapotranspiration, and snow water equivalent for the two catchment case studies.

\section{Methods}

\subsection{Low-flow indicator}

The low-flow indicator chosen here is the mean annual minimum flow over 7 days (MAM7) (WMO, 2008). This choice 
Table 3. HM characteristics. KGE refers to the Kling-Gupta efficiency (Gupta et al., 2009).

\begin{tabular}{lllll}
\hline Acronym & Project partner & Type/distributed & Calibration & Reference \\
\hline GR5J & Irstea HBAN & Conceptual/no & Optimization on $\operatorname{KGE}(\sqrt{Q})$ & Pushpalatha et al. (2011) \\
MORDOR & EDF DTG & Conceptual/no & Optimization on $\operatorname{KGE}(Q)$ & Garçon $(1999)$ \\
CEQUEAU & EDF R\&D & Conceptual/yes & Semi-distributed optimization on multiple criteria & Hendrickx $(2001)$ \\
J2000 & Irstea HHLY & Conceptual/yes & Manual sensitivity analysis & Krause (2002) \\
CLSM & UMR METIS & Physically based/yes & Manual calibration on $\operatorname{KGE}(Q)$ and bias & Ducharne et al. (2000) \\
ORCHIDEE & UMR METIS & Physically based/yes & No calibration & Krinner et al. (2005) \\
\hline
\end{tabular}

was guided by the requirement for (1) an annual indicator and (2) an indicator commonly used internationally for operational purposes. In Alpine catchments influenced by snowpack/snowmelt processes, two distinct low-flow periods can be identified with different underlying physical processes (see e.g. Laaha and Blöschl, 2006a, b; Laaha et al., 2013). Summer low flows occur as a consequence of persistent dry and warm weather periods when evaporation exceeds precipitation. Winter low flows occur when precipitation is temporarily stored in the snow cover causing runoff recession. Two distinct seasons are therefore considered for computing the MAM7: summer (1 June-31 October) and winter (1 November-31 May). Figure 2 shows these two low-flow seasons and the observed daily interannual regime over the REF period for the two catchment case studies. Low-flow seasons are less well marked for the low-elevation Verdon@Sainte-Croix which experiences a higher interannual variability of autumn flows due to potentially heavy rainfall events.

\subsection{The quasi-ergodic ANOVA framework}

\subsubsection{General principles}

The partitioning of uncertainties in hydrological projections is performed in the framework of the quasi-ergodic analysis of variance (QE-ANOVA) framework developed by Hingray and Saïd (2014). This framework allows disentangling model uncertainty from internal variability in any unbalanced multimember multimodel ensemble, as the one available here. Model uncertainty components are estimated from the noisefree change signals (NFSs) of the different modelling chains using a classic analysis of variance framework. Internal climate variability components are then estimated based on the residuals from the NFSs, relying on the quasi-ergodic assumption for transient climate simulations. The paragraph below describes briefly the QE-ANOVA framework and the reader is referred to Hingray and Saï (2014) for more details on the methodology, and to Lafaysse et al. (2014) for an application to hydrological variables.

Previous applications of the QE-ANOVA framework focused on changes in time-slice averages of the raw data $y$. In the following equations, the variable studied is noted $Y$ and represents such a time-slice average. Equation (2) defines

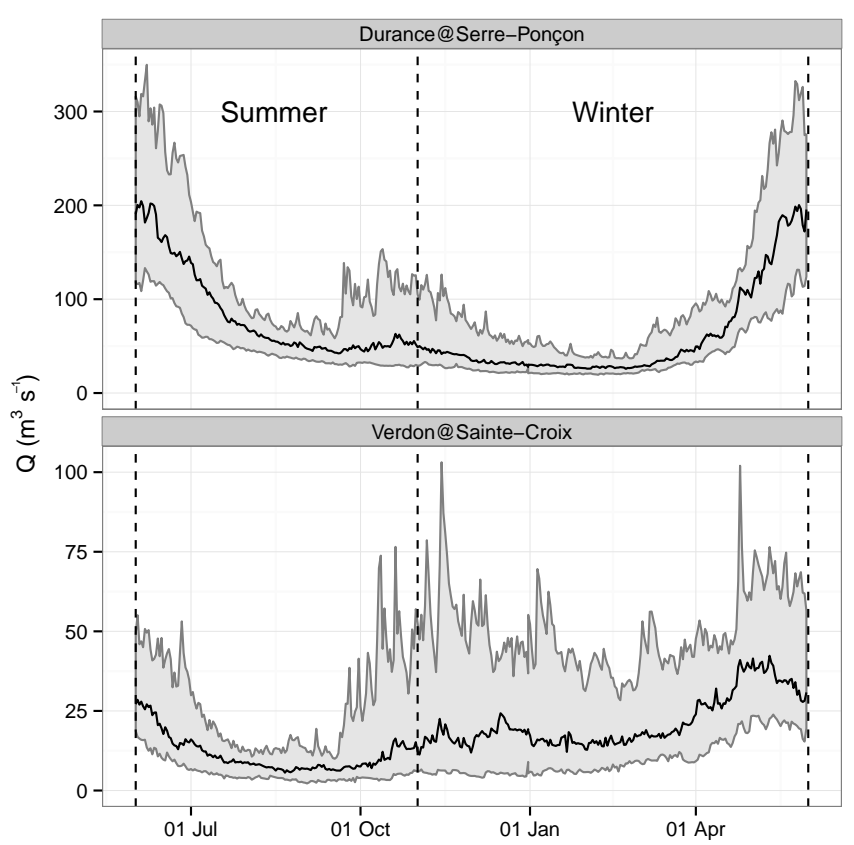

Figure 2. Daily interannual regime of naturalized streamflow over the REF period for the two catchment case studies, and season boundaries for low-flow analysis. Grey ribbons frame the first and last deciles and the black line shows the median value.

the relative change of the variable studied $Y$ with respect to a baseline $Y_{0}$, for any prediction lead time $t$ :

$\Delta(g, s, h, r, k, t)=\frac{Y(g, s, h, r, k, t)}{Y_{0}}-1$,

where $g, s$, and $h$ are indices over GCMs, SDMs, and HMs, respectively, $r$ is an index over runs from a given GCM, and $k$ an index of stochastic realizations from a given SDM. In the following, $m$ will denote a GCM-SDM-HM modelling chain as short for $(g, s, h)$. The relative change $\Delta$ may be written as

$\Delta(m, r, k, t)=\operatorname{NFS}(m, t)+\eta(m, r, k, t)$,

where NFS $(m, t)$ is the noise-free signal (NFS) of the change variable for chain $m$, i.e. the estimated response of the modelling chain, and $\eta(m, r, k, t)$ are the residuals of stochastic realization $k$ of SDM $s$ for the run $r$ of GCM $g$. The total 
uncertainty of $\Delta$ corresponds to the sum of variances of both terms on the right-hand side of Eq. (2). They correspond respectively to the model uncertainty and to the internal variability of $\Delta$ for the modelling chains. Their different components are estimated as follows.

\subsubsection{Deriving noise-free change signals (NFSs)}

NFSs are estimated by first fitting trend models to the raw data $y$ for each of the modelling chains, considering all available GCM runs and all SDM stochastic realizations available for this specific chain. NFSs are then obtained by considering relative changes of these trend models with respect to the baseline $Y_{0}$ :

$\operatorname{NFS}(m, t)=\frac{\hat{y}(m, t)}{Y_{0}}-1$,

where $\hat{y}$ is the trend model output. In the present work, $Y_{0}$ is taken as the average of the trend model over the reference period for a given modelling chain:

$Y_{0}(m)=\left.\overline{\hat{y}(m, t)}\right|_{t \in \mathrm{REF}}$.

This choice has also been made by Bracegirdle et al. (2014) and is similar to the approach of Charlton-Perez et al. (2010), who considered changes with respect to a fitted trend value for a given reference year.

\subsubsection{Partitioning model uncertainty}

NFSs can be partitioned into GCM, SDM, and HM contributions through a three-way ANOVA according to the following equation:

$\mathrm{NFS}(m, t)=\mu(t)+\alpha(g, t)+\beta(s, t)+\gamma(h, t)+\epsilon(m, t)$,

where $\mu(t)$ is the overall climate response representing the grand ensemble mean of all projections at time $t ; \alpha(g, t)$, $\beta(s, t)$, and $\gamma(h, t)$ are the main effects of GCM $g, \operatorname{SDM} s$, and $\operatorname{HM} h$, respectively; and $\epsilon$ is the residual that may partly be due to model interactions. The empirical variances associated to these different effects correspond to the different components of model uncertainty - namely GCM, SDM, and HM uncertainty - and of residual/model interaction uncertainty, noted RMI in the following. The three-way ANOVA on NFSs moreover allows identifying individual model effects, i.e. average deviations of the NFSs from the grand ensemble mean $\mu$ due to a given model, be it a GCM, a SDM, or a HM.

\subsubsection{Partitioning internal variability}

The internal climate variability variable $\eta$ in Eq. (2) can be partitioned into a large-scale and a small-scale component. The first one originates from the internal/natural fluctuations of the climate and the latter results from the variability in local meteorological situations observed given a large-scale atmospheric configuration. In the present multimember multimodel ensemble, the large-scale internal variability (LSIV) stems from GCM internal variability. For a modelling chain driven by a given GCM, the LSIV leads to the fluctuations around the long-term trend simulated with that chain. It also corresponds for any prediction lead time to the dispersion between projections obtained or that would be obtained for different runs of this GCM. The small-scale internal variability (SSIV) originating here from a stochastic SDM is expressed as the dispersion of the different stochastic realizations of a SDM for a given lead time.

For the present ensemble of projections, estimates of both internal variability components are derived with the quasiergodic assumption of transient climate simulations for relative change variables, following Appendix B of Hingray and Said (2014). This assumes that the variance of the studied variable - or more precisely, the coefficient of variation is constant over the whole simulation period. In the present study, and conversely to the previous work, the baseline used for the estimation of the change variable is a constant $Y_{0}(\mathrm{~m})$ that depends only on the modelling chain $m$. The expressions of $\operatorname{SSIV}(t)$ and $\operatorname{LSIV}(t)$ given by Hingray and Saïd (2014) thus simplify. They are given in Appendix A.

\subsection{Application of the QE-ANOVA framework to low flows}

\subsubsection{Choice of NFS}

Simple linear trend models are used to fit MAM7 projections of the whole period considered (1980-2065), on the contrary to Hingray and Saïd (2014), who considered piecewise NFSs composed of a constant value over a control period and a linear or polynomial trend over a transient period separated by a pivot year. The choice of a unique trend model is motivated by the shorter and wholly transient period considered here. Indeed, the pivot year has been estimated as 1950 and 1980 for temperature and precipitation, respectively, for the Durance@Serre-Ponçon by Hingray and Saïd (2014). The choice of a linear trend - following Hingray and Saïd (2014) for precipitation - was made not to overfit large interannual fluctuations of the low-flow indicator.

A total of 72 linear trend models were fitted, one for each modelling chain, i.e. for each combination of GCM, SDM and HM. The NFS of each modelling chain is then obtained by considering relative changes with respect to the average of the trend model for the associated chain over the 1980-2009 REF period following Eq. (4).

Figure 3 shows an example of winter low-flow NFS for the Durance@ Serre-Ponçon, for the IPCM4 GCM, the d2gen SDM, and the CLSM HM. This specific NFS is a decrease reaching around $-25 \%$ in 2065 when the grand ensemble mean shows a much smaller decrease. This figure also exemplifies the prominent contribution of internal variability 


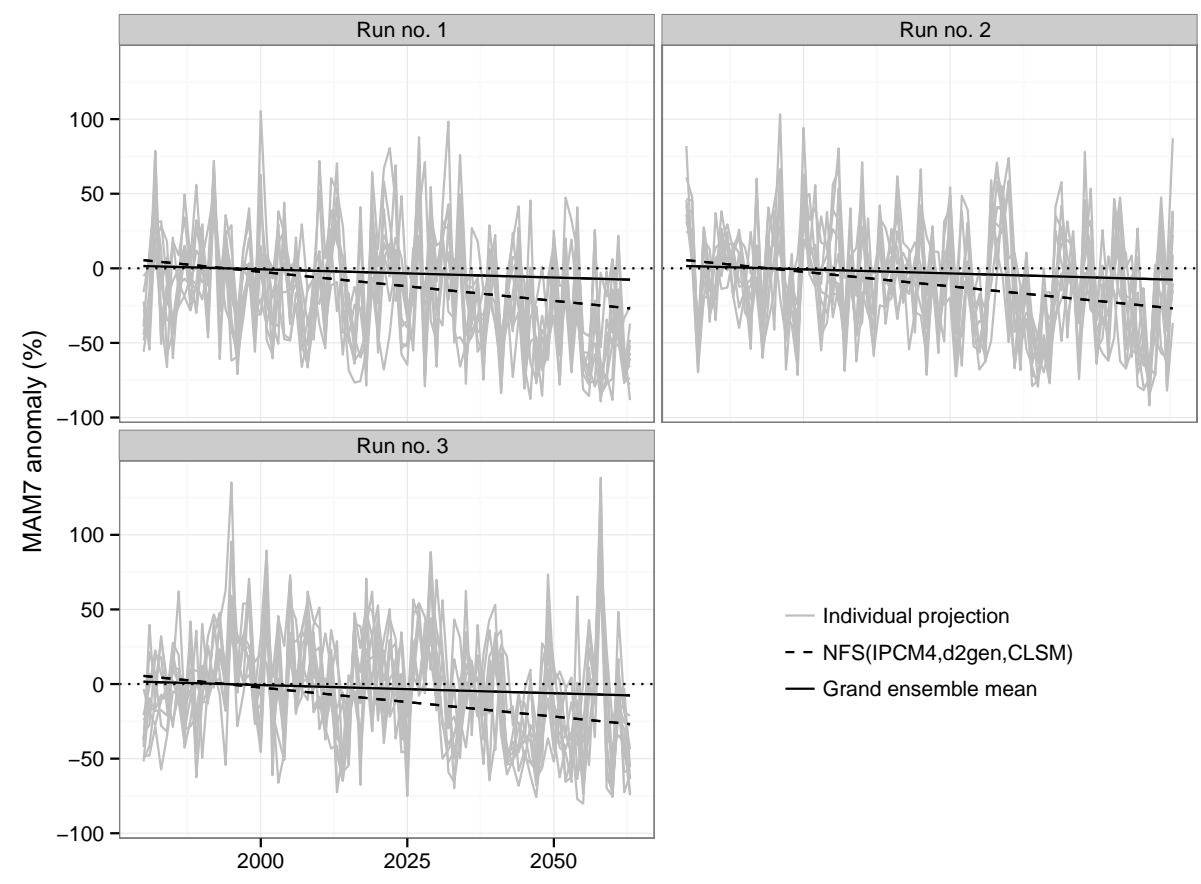

Figure 3. Winter low-flow NFS( $g=$ IPCM4, $s=\mathrm{d} 2 \mathrm{gen}, h=\mathrm{CLSM})$ for the Durance @ Serre-Ponçon, fitted to all 30 projections available as combinations of the IPCM4 GCM (3 runs), the d2gen SDM (10 realizations), and the CLSM HM. Each panel shows $10 \mathrm{~d} 2 \mathrm{gen}$ realizations from a given IPCM4 run as well as the common NFS and the grand ensemble mean.

components - within panel for SSIV and across panels for LSIV - compared to the change signal from this particular modelling chain, but also compared to the grand ensemble change signal.

\subsubsection{Extending the framework to uncertainties in yearly anomalies}

In this study, the QE-ANOVA framework is extended for partitioning the uncertainties not only on changes in time-slice averages as in the previous applications but also on yearly anomalies of the raw values, in order to capture the effects of year-to-year variability in the quantification of uncertainties. The studied variable $Y$ in Eq. (2) is therefore taken as either $y$ - the raw yearly variable - or $\bar{y}$ - a 30 -year rolling average. Uncertainty analyses on both yearly values and time-slice averages will be presented in parallel in the next section. It has to be noted that in both cases, NFSs are fitted to the yearly data, resulting in a similar decomposition of model uncertainty sources through the three-way ANOVA.

\subsubsection{Deriving transient low-flow confidence bounds}

The total variance and grand ensemble mean computed through the QE-ANOVA approach allows deriving transient confidence bounds for the evolution of low flows, provided that an assumption is made on the shape of the distribution. Following previous uncertainty decomposition work on decadal averages, a normal distribution is selected for 30- year low-flow averages (see e.g. Hawkins and Sutton, 2009; Charlton-Perez et al., 2010; Hawkins and Sutton, 2011). A lognormal distribution is selected here for yearly values in order to take account of the skewed and bounded distribution of low flows, and appropriate lognormal distribution parameters have been derived from the grand ensemble mean and the total variance (see Appendix B). Additionally, the confidence range may be partitioned into the different sources of uncertainty identified by the QE-ANOVA approach in order to provide a transient evolution of these uncertainties.

\subsubsection{Detecting the time of emergence of a low-flow change signal}

Having transient probabilistic projections further allows detecting the time of emergence (ToE) of a change signal in low flows, i.e. the time when this signal emerges from the underlying variability and uncertainty noise (Giorgi and $\mathrm{Bi}$, 2009). We define here the ToE as the first time when the $95 \%$ confidence interval of low-flow anomalies - either yearly or 30 -year rolling averages - does not include the zero change. This ToE is therefore determined in a transient way, more on the line with the approach of Hawkins and Sutton (2012) than with the few recent hydrological applications in which it is only resolved at the 20- to 30-year timescale (see e.g. Köplin et al., 2014).

The ToE analysis described above is also applied to perfect hydrometeorological chains, i.e. chains with no GCM, 
SDM, or HM uncertainty. The total variance is in this case estimated from internal variability components and residuals only, and the grand ensemble mean is retained from the analysis with actual modelling chains. Note that the latter assumption requires adopting a truth-centred paradigm (see e.g. Knutti et al., 2010) for all model types, which is still controversial for GCMs (see e.g. Sanderson and Knutti, 2012). The corresponding confidence interval thus allows to assess the potential to detect as early as possible the ToE when considering only the irreducible part of the future uncertainty, following the framework developed by Hawkins and Sutton (2009, 2011).

\subsection{Investigating HM contribution to uncertainty in low-flow changes}

A specific issue of interest in this study is the dependence of the low-flow evolution on the HM used, all other things being equal. The fraction of variance due to the HMs in the whole ensemble of hydrological projections as given through the QE-ANOVA approach described above is checked against a simple single-time ANOVA decomposition approach proposed by von Storch and Zwiers (1999, chap. 9) and recently applied by Christierson et al. (2012) for a similar hydrologyclimate partitioning purpose. The fraction of variance due to the HMs is estimated for each prediction lead time based on only data for that lead time, conversely to the time series approach of QE-ANOVA. It is computed as

$R_{a}^{2}=\frac{\mathrm{SSA}-\frac{p-1}{p(n-1)} \mathrm{SSE}}{\mathrm{SST}}$,

where SSA is the treatment sum of squares, SSE the error sum of squares, SST the total sum of squares, $p$ the number of HMs (6), and $n$ the number of different climate projections used to force each HM (330).

Potential sources for the HM contribution to the total uncertainty are further investigated through the evolution of selected HM state variables potentially relevant for explaining the evolution of summer and/or winter low flows. Computed summer low flows in snow-influenced catchments depend on two main factors other than external meteorological forcings: evapotranspiration and previous winter snowpack. More precisely, both Godsey et al. (2014) and Jenicek et al. (2016) suggested maximum snow water equivalent (maxSWE) as a relevant predictor for summer minimum low flows. Drivers of computed winter low flows are a bit harder to identify. Three hydrological drought types identified by Van Loon et al. (2015) for cold climates are relevant for assessing winter absolute low flows. On one hand, the "cold snow season drought" and the "warm snow season drought" are closely related to the timing of snowpack accumulation/melt, indicators of which are difficult to extract from time series (see e.g. Whitfield, 2013). On the other hand, the "rain-to-snowseason drought" describes the continuation of preceding water deficit into winter (see also Van Loon et al., 2010). All

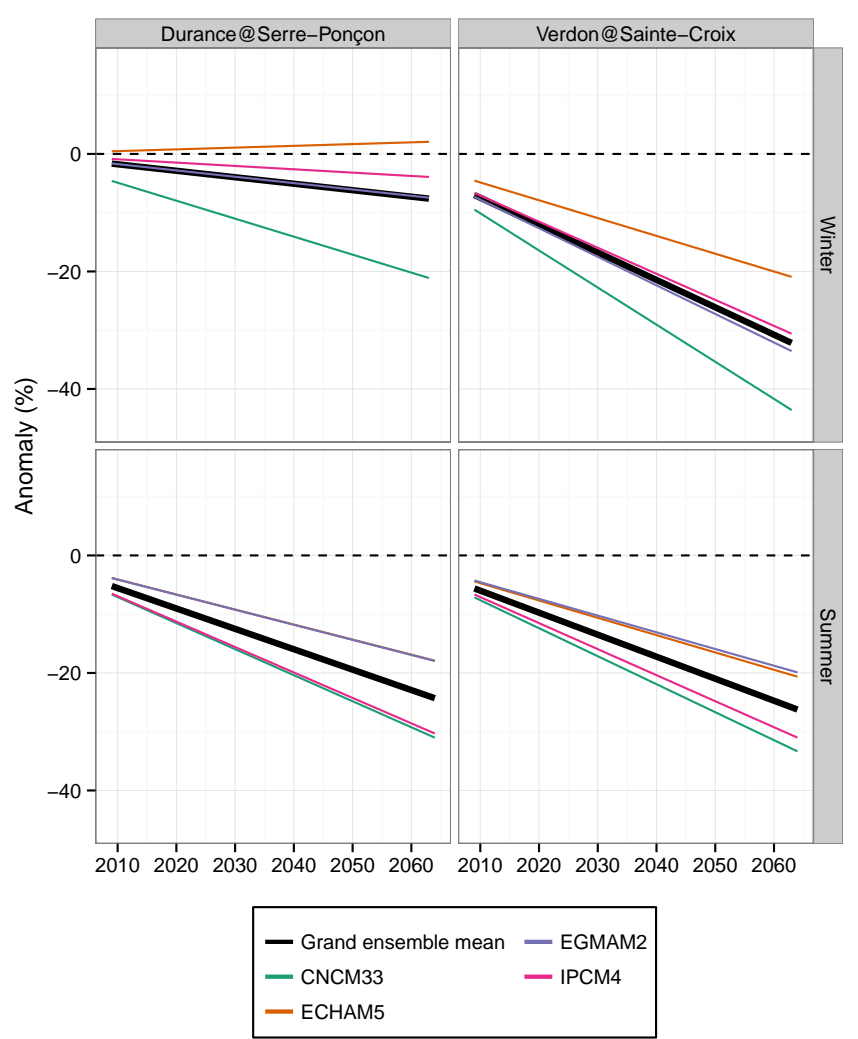

Figure 4. GCM effects on low-flow changes around the grand ensemble mean for both catchments and both seasons.

external meteorological forcings like total precipitation being equal, only differences in modelled evapotranspiration can be in this case retained as a potential source of HM contribution in winter low-flow uncertainty. The two selected HM state variables for both seasons are therefore the mean annual actual evapotranspiration (AET) and the maxSWE. AET and maxSWE output time series are extracted for all 1980 hydrological projections. Noise-free signals are extracted from these series in the same way than for low flows (see Sect. 3.2.2), and HM effects are derived from these NFSs (see Sect. 3.2.3). Comparing HM effects on low-flow changes with HM effects on AET/maxSWE may confirm possible drivers of the divergence, even if no causal relationship can be actually drawn.

\section{Results}

\subsection{Individual model effects on low-flow changes}

Figure 4 shows individual GCM effects around the grand ensemble mean. Looking first at this grand ensemble mean, low flows are projected to decrease in both catchments and in both seasons. However, when the decrease in 2065 is around only $-7 \%$ of the 1980-2009 average for the Durance in winter, it reaches $-25 \%$ in summer for both catchments and 


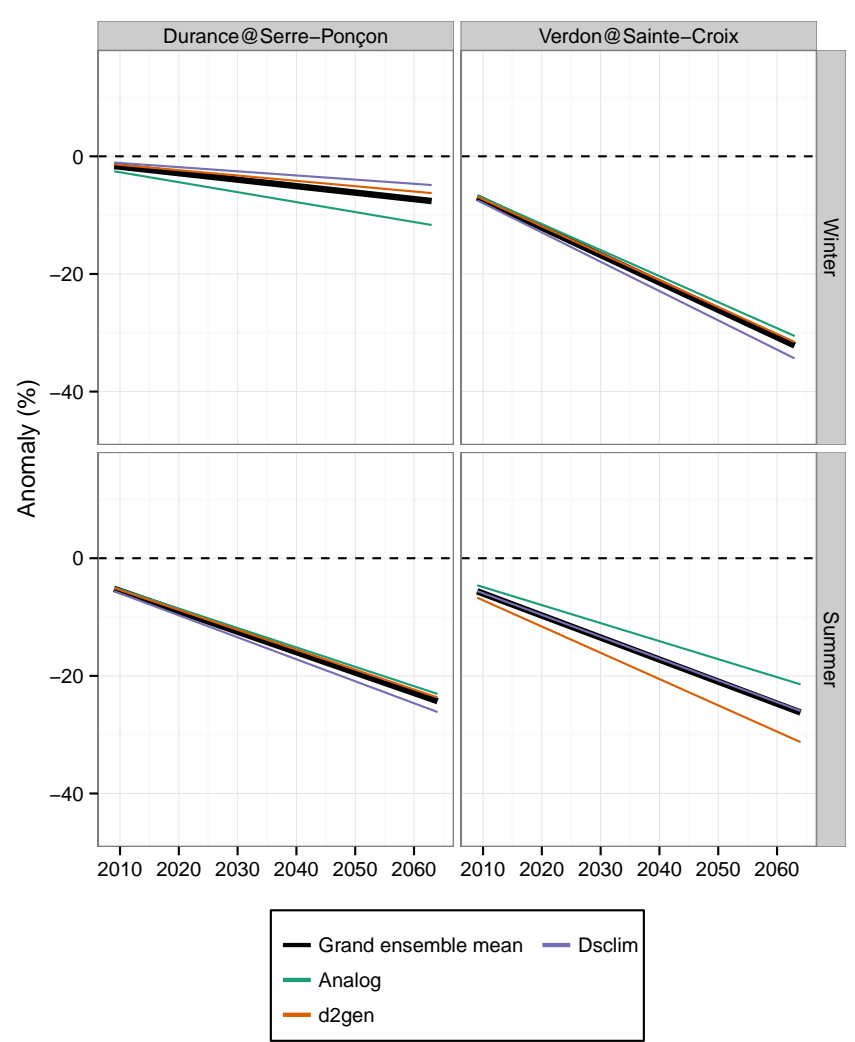

Figure 5. As for Fig. 4, but for SDM effects.

even exceeds $-30 \%$ in winter for the Verdon. The dispersion between GCM effects around the grand ensemble mean is quite large in winter, leading to changes ranging, for example, from -20 to $+2 \%$ for the Durance in 2065. The range of GCM effects is more limited in summer, but still higher than $10 \%$ in 2065. CNCM33 (respectively ECHAM5) tends to systematically give a larger (respectively lower) decrease than the grand ensemble mean. IPCM4 (respectively EGMAM2) also gives a larger (respectively lower) decrease, but only in summer.

Figure 5 shows individual SDM effects around the grand ensemble mean. Individual SDM effects are not homogeneous over catchments and seasons, with analog for example generating a stronger decrease for the Durance in winter and a smaller one for the Verdon in summer. In the other two situations, the dispersion between SDM effects is hardly noticeable.

Figure 6 shows individual HM effects around the grand ensemble mean. The dispersion is here generally very large, with ranges of more than $30 \%$ for the Durance in winter and for the Verdon in summer. The dispersion is more limited for the Verdon in winter. Looking into more details at individual models, ORCHIDEE stands as an outlier for the Durance in winter with a projected decrease of $-28 \%$ in 2065. Similarly, CLSM projects a much more severe decrease than other models in summer for both catchments. J2000 contrar-

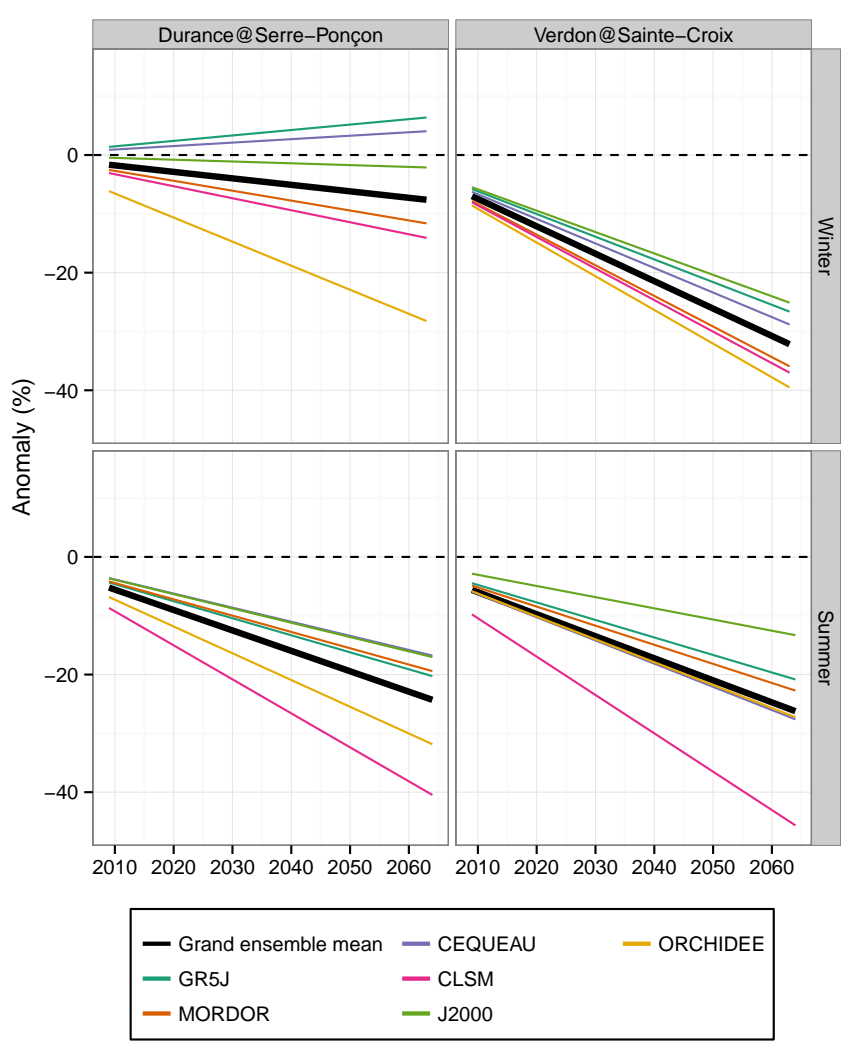

Figure 6. As for Fig. 4, but for HM effects.

ily tends to generate a smaller decrease than the grand ensemble mean in all four cases.

\subsection{Time-dependent hierarchy of the different sources of uncertainty}

The contribution of each source of uncertainty quantified by the QE-ANOVA approach can be expressed as a fraction of the total variance for each lead time $t$ (see e.g. Hawkins and Sutton, 2011). Figure 7 shows this decomposition of total variance for 30-year rolling average of low-flow changes in both catchments and both seasons. As shown in many previous studies (see e.g. Hawkins and Sutton, 2011), internal variability components contribute for the most part of the total variance for short lead times. They remain generally above $20 \%$ in 2065 and around $45 \%$ for the Verdon in winter. Large-scale internal variability accounts for around threequarters of the total internal variability. The decomposition of model uncertainty into GCM, SDM, and HM contributions reveals interesting features: first, GCMs accounts for $15-25 \%$ of the total variance at the end of the period, and SDMs for less than $6 \%$, with even negligible contributions for the Verdon in winter and for the Durance in summer. HM contribution to total variance is however largely not negligible. Values in 2065 reach $35 \%$ in summer for both catchments and even $43 \%$ for the Durance in winter. The Verdon 


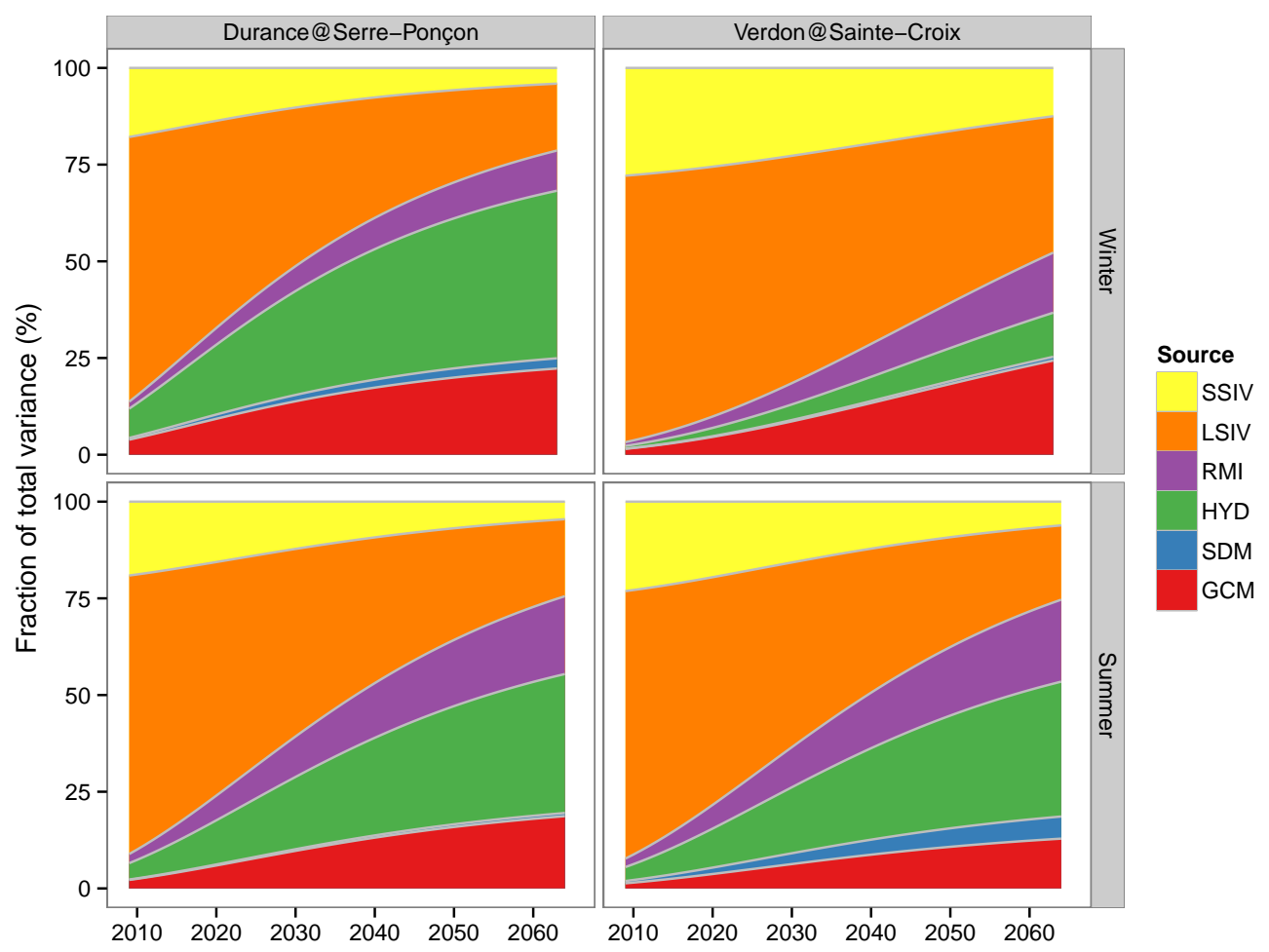

Figure 7. Fraction of total variance explained by each source of uncertainty for 30-year rolling averages of low-flow changes with respect to the REF period average. Values are plotted in the middle of each time slice.

in winter is the only case where values remain around $10 \%$. Lastly, residuals and model interactions generally account for $10-20 \%$ of the total variance.

Figure 8 shows a similar decomposition of total variance in both catchments and both seasons, but for yearly low-flow anomalies. The most striking point is the very large contribution of internal variability components in all cases and for all lead times, up to more than $80 \%$ in 2065 , and even $94 \%$ for the Verdon in winter. Such a prominence of internal variability is clearly visible in individual time series plots like Fig. 3, where the change signal of the considered NFS is yet rather high. Small-scale internal variability generally accounts here for one-third of the total internal variability uncertainty. By construction of the NFSs, the remaining part of variance due to model uncertainties divides up into GCM, SDM, HM, and residuals (RMI) in the same way as for time-slice averages in Fig. 7.

\subsection{Projected evolution and associated confidence bounds}

Figure 9 shows the evolution of 30-year average changes in low flows and associated confidence bounds for both catchments and for both seasons. The total uncertainty increases with lead time in all cases and by a factor of 2.5 between 2009 and 2065 in summer, more than 3.5 for the Durance in winter, and only 1.3 for the Verdon in winter. The main con- tributor to this increase is HM uncertainty followed by GCM uncertainty. For the Verdon in winter, a decrease in both internal variability components nearly offsets this increase in model uncertainty.

Figure 10 plots the evolution of low-flow yearly anomalies. The difference with respect to Fig. 9 lies in the amplitude of internal variability components. Moreover, they both tend to decrease with lead time as a consequence of the decrease in the grand ensemble mean. Their evolution counterbalances the increase in model uncertainties, leading to a reduction in total uncertainty in all cases except the Durance in winter.

\subsection{Time of emergence of a low-flow decrease and potential to reduce uncertainty}

Figure 9 suggested that the probability of a 30 -year average low flow lower than the REF period average could be very close to 1 after 2050, except for the Durance in winter. Blue curves in Fig. 11 show the evolution of this probability along the period considered. Except for the Durance in winter where the change signal is too weak compared to uncertainties, the probability of a negative change between the REF period and a future period reaches $95 \%$ in 2033-2039, that is for 30-year time slices starting around 2020.

Red curves in Fig. 11 show the probability of a low flow for a given year being lower than the REF average. This second probability remains below $90 \%$ even at the end of the 


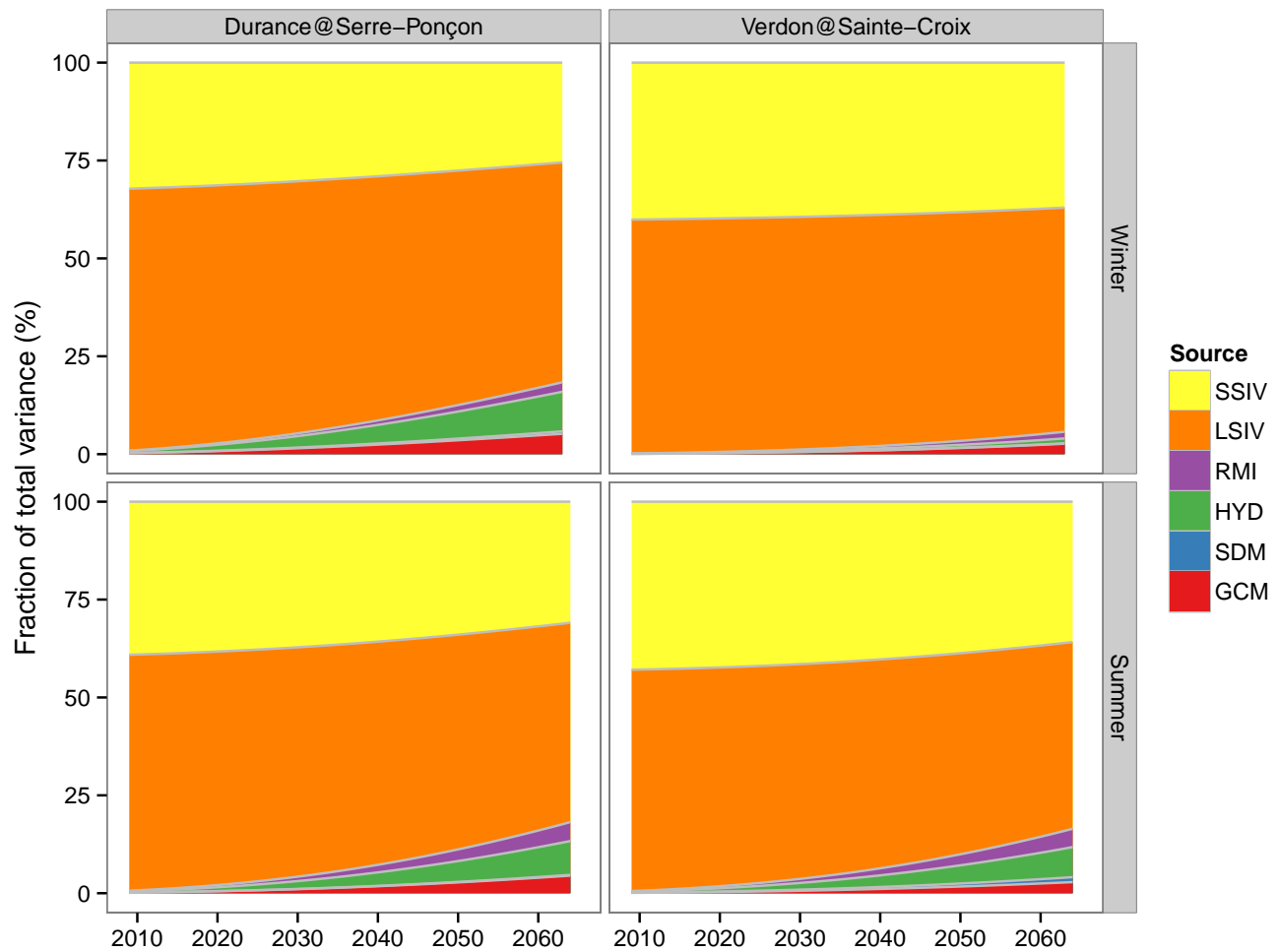

Figure 8. As for Fig. 7, but for yearly low-flow anomaly with respect to the REF period average.

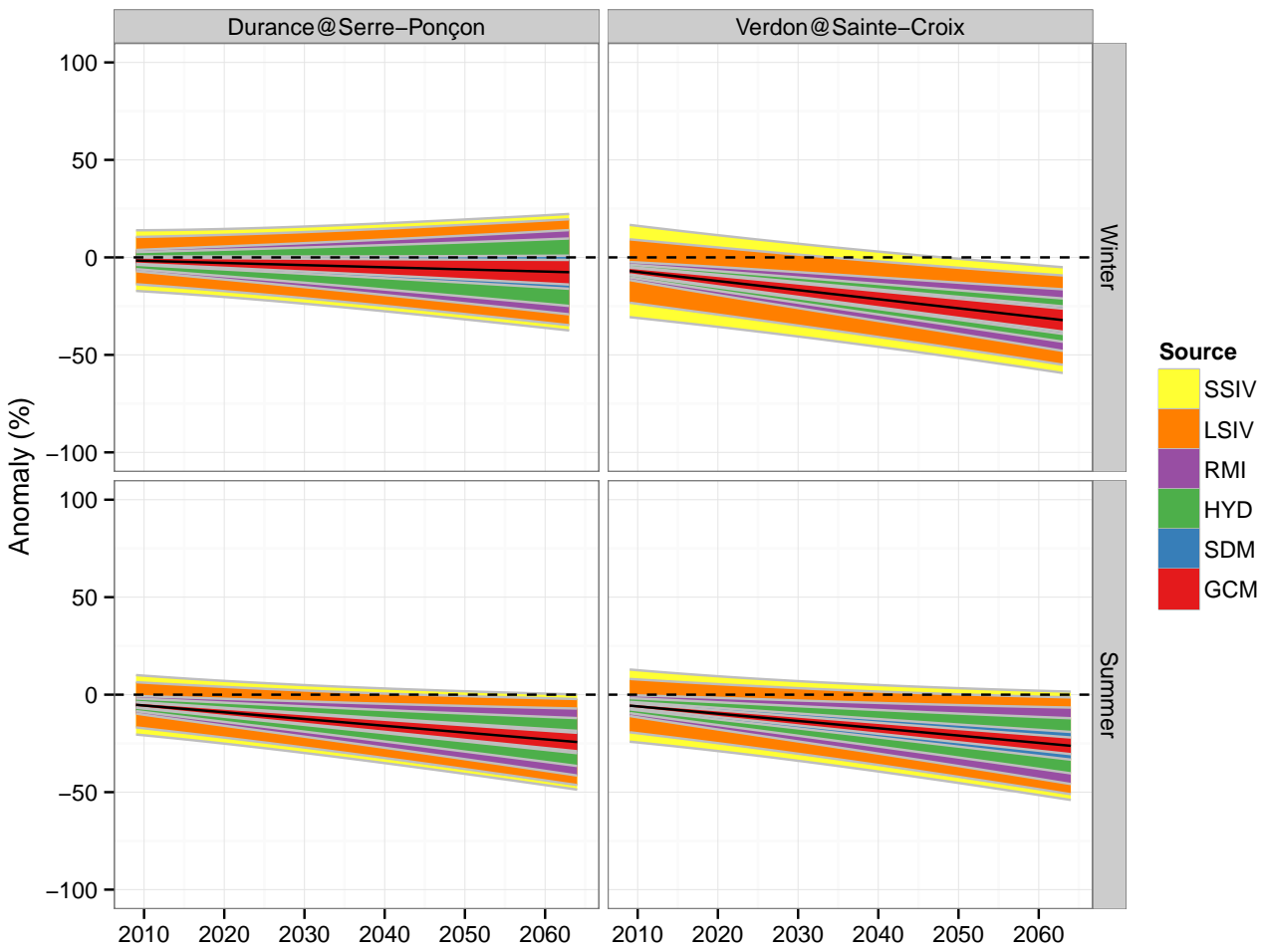

Figure 9. Projected changes in 30-year averages of low flow for both stations and seasons, together with a partitioning of the $90 \%$ confidence interval into the different uncertainty sources (see text for details). Values are plotted in the middle of each time slice. The fraction of the confidence interval for a given source of uncertainty is proportional to the standard deviation of its contribution to the total standard deviation, following Hawkins and Sutton (2011) and Hingray and Saïd (2014). 


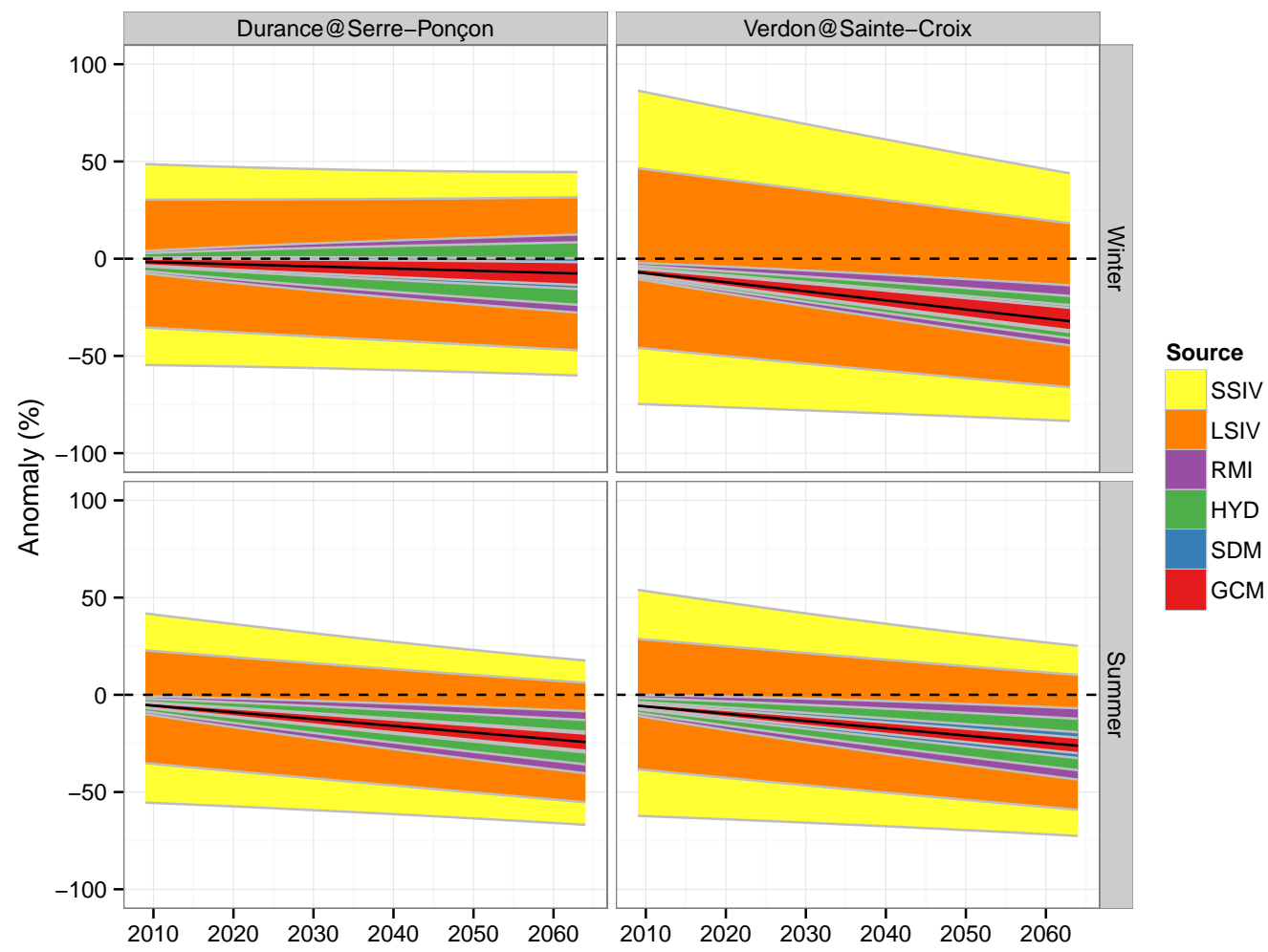

Figure 10. As for Fig. 9, but for yearly anomalies.

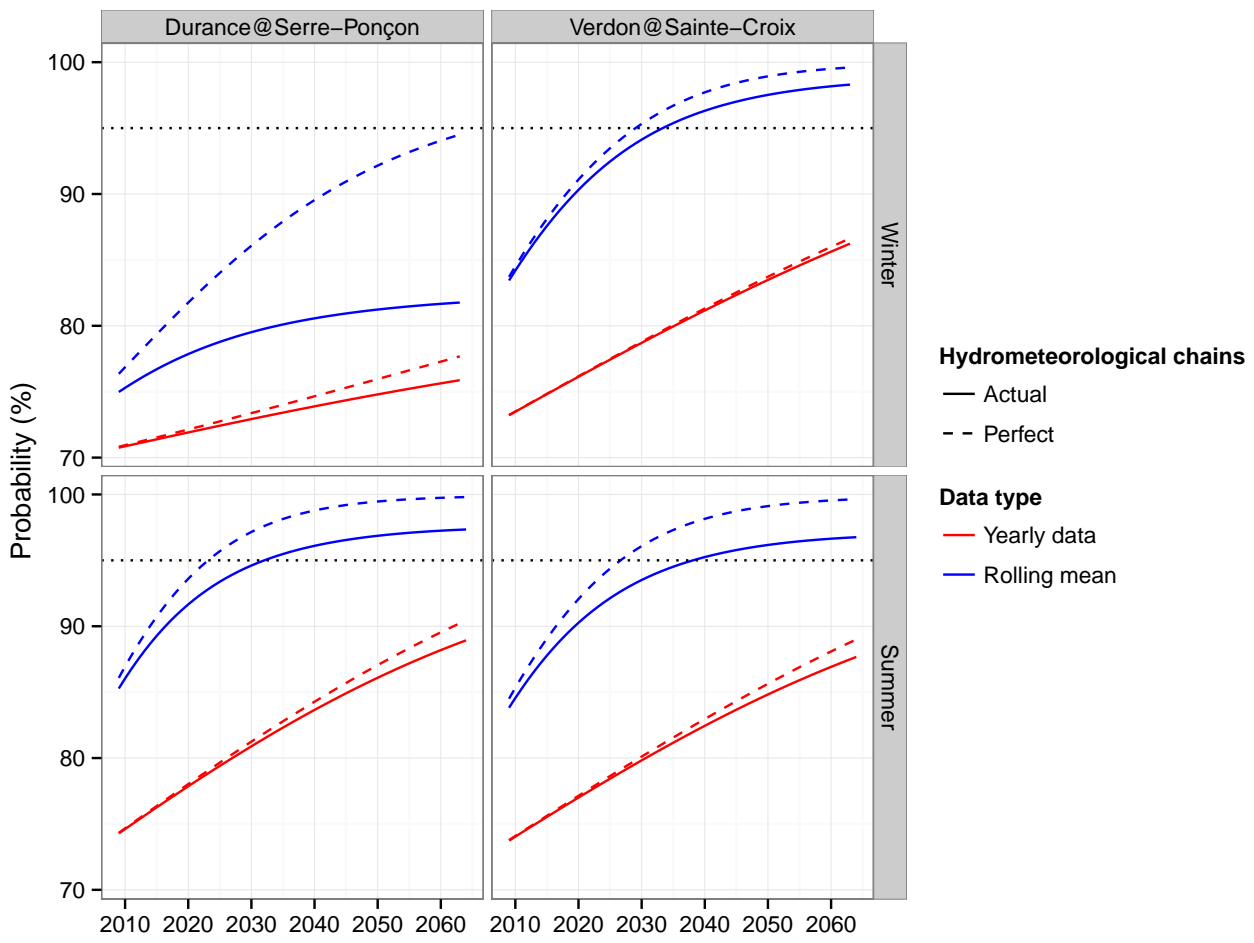

Figure 11. Evolution of the probability of a low flow below the REF period average, for yearly anomalies and 30-year rolling averages, with the hydrometeorological model chains used here and with a perfect hydrometeorological model (see text for details). 




Figure 12. Fraction of total uncertainty due to HMs computed from the QE-ANOVA and a simpler approach (see text for details), for both yearly anomalies and changes in 30-year rolling averages.

period in all cases. It thus prevents to draw any definitive conclusion on the sign of the yearly anomaly with respect to the REF period average for any given lead time up to the end of the studied period.

Figure 11 also shows the potential to reduce the uncertainty in low-flow projections and, more specifically, its effect on the estimation of the probability of a low-flow decrease. Dashed lines in Fig. 11 denote results that would be obtained with a perfect hydrometeorological model chain. The probability of a low-flow decrease is of course higher in all cases. For yearly anomalies, due to the large contribution of internal variability components, using a perfect modelling chain still does not allow to detect the ToE within the time horizon considered. However, for 30-year rolling averages, the ToE at the $95 \%$ confidence level can be detected around a decade earlier for both catchments in summer, and can be estimated at 2070 for the Durance in winter, where the signal is not expected to emerge within the considered time horizon using the actual modelling chains.

\subsection{Further analysis on HM contribution to the total uncertainty}

Figure 7 highlighted the large and growing part of total uncertainty due to HMs on low-flow projections in summer for both catchments, and in winter for the Durance. In order to check this high level of HM contribution, results from QEANOVA are compared in Fig. 12 to a simpler approach for computing the fraction of variance explained by HMs. Due to internal variability, estimates from the single-time approach for yearly low-flow anomalies are very noisy from one year to the next. QE-ANOVA results are quite consistent with this simpler approach and interestingly propose a smoother and more robust version of it. Figure 12 also shows a similar comparison for 30-year rolling averages and proposes similar conclusions, except that the noise in the simple approach estimates occurs at the multidecadal timescale.

The drivers of this high HM contribution to the total uncertainty - i.e. the origin of effects from individual HMs shown in Fig. 6 - may be traced back to the HM-specific computation of model state variables, namely AET and maxSWE. Figure 13 first shows that HM effects on AET are negatively correlated with HM effects on low flows in both catchments and both seasons. Otherwise put, HMs showing a stronger increase in evaporation tend to simulate a stronger decrease in low flows. It is important to note that this somewhat reasonable relation is, however, not significant for summer flows at the $90 \%$ confidence level. In summer, and for the Durance only, effects on low flows are significantly correlated with effects on the other potential driver (maxSWE). The slope of the relationship corresponds to around $20 \%$ of reduction in low flows for each $10 \%$ reduction in maxSWE. The relation between effects on low flows and effects on maxSWE for the Verdon in summer is not significant and has a gentler slope.

\section{Discussion}

\subsection{QE-ANOVA advantages and limitations for future low-flow analysis}

The approach used here provides a transient evaluation of uncertainties in yearly values or time-slice rolling averages in future low flows. It notably allows to estimate the ToE of a decrease signal in low flows. The time series approach at the heart of the QE-ANOVA framework makes this estimation rather robust. This would not have been the case with other uncertainty estimation approaches such as the one proposed by Yip et al. (2011), due to the high year-to-year variability in the low-flow indicator (and more generally on any catchment-scale hydrological indicator). Smoothing out such variability may allow the water manager mentioned in the introduction to have a clear view on the probability of crossing any management-relevant threshold for any year in the future, and therefore anticipate when such probabilities will not be compatible any more with current management options, facilities, and regulations. Moreover, water management rules rely on long-term average water available during the low-flow season, but also on thresholds related to individual low-flow values reached for a given year. The two timescales studied here may thus contribute to build more robust adaptation strategies than the ones based solely on changes in 30-year time-slice averaged quantities, which has been the focus of many studies until now. It has to be noted that such ToE estimates are intrinsically linked to the choice 


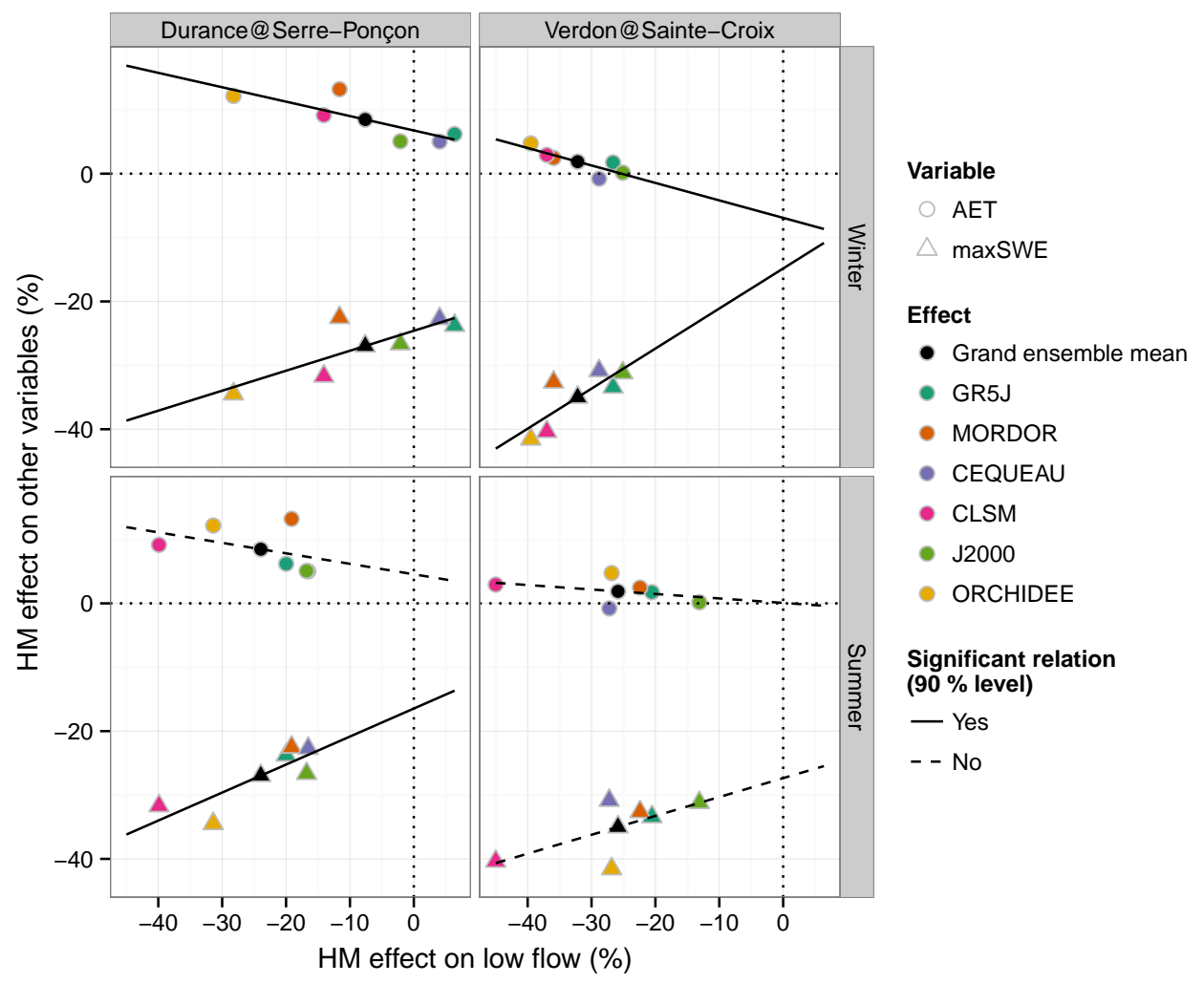

Figure 13. Relations between HM effects on low-flow anomaly and HM effects on AET/maxSWE anomaly for the year 2065. Significant relations at the $90 \%$ confidence level are shown with solid lines.

of the reference period chosen for calculating the anomalies (see Hawkins and Sutton, 2016, for relevant comments on this issue).

More generally, all above statements rely on the assumptions of both the QE-ANOVA framework described in Sect. 3.2 and the further choices made for this specific application to yearly low-flow indicators (see Sect. 3.3). Four points are discussed below. First, the QE-ANOVA framework was retained for studying this complex uncertainty design partly because it critically allows to disentangle largescale and local-scale variability, which is not the case with other recently published ANOVA methods (see e.g. Northrop and Chandler, 2014). Second, the simple linear trend model adopted likely overestimates both the LSIV and the SSIV (see Raïsänen, 2001; Hingray and Saïd, 2014, for discussions on this issue). However, this is clearly the most reasonable choice when dealing with indicators with a high interannual variability. Third, the slight decrease in internal variability components that can be spotted in Fig. 9 is related to the quasi-ergodic assumption of a constant coefficient of variation in the low-flow indicator and the fact that the grand ensemble mean actually decreases. Fourth, this assumption may be relaxed for SSIV by computing yearly empirical values of the variance terms over stochastic downscaling realizations in Eq. (A1). Comparing the temporal evolution of SSIV with and without the quasi-ergodic assumption shows that this assumption is quite reasonable (see Fig. S1 in the Supplement). The only discrepancy may be spotted for the Durance in winter, where the SSIV shows a slight decrease (respectively increase) with (respectively without) the quasiergodic assumption. This would have very little impact on derived estimates like ToE because of the very limited change signal for this catchment in winter (see Figs. 10 and 11). Similarly to SSIV, it is possible to relax this assumption for LSIV, even if in degraded mode (1) because of the different numbers of runs from each GCM, and (2) more importantly because of the fact that two out of four GCMs only have one run. The temporal evolution of the variance terms in Eq. (A3) may indeed be computed empirically for any $m$ where $r>1$. The quasi-ergodic assumption is again confirmed by comparing the temporal evolution of LSIV with and without this assumption, using the two GCMs with multiple runs (see Fig. S2 in the Supplement).

\subsection{HM contribution to total uncertainty}

The HM contribution to total uncertainty shown in Fig. 12 is higher than values obtained in other studies for other hydrological indicators like monthly flows (see e.g. Christierson et al., 2012; Bosshard et al., 2013). However, it is consistent with recent findings that HM uncertainty in low-flow changes is higher than GCM uncertainty in snow-dominated 
catchments (see e.g. Giuntoli et al., 2015). Indeed, low flows are strongly linked to catchment processes that may be represented differently in different HMs. It is therefore understandable that the contribution of HMs to the total uncertainty is higher than, say, for annual flood peak projections.

Possible drivers of the divergence in HM responses has been explored through the analysis of changes in model state variables AET and maxSWE. Figure 13 highlighted the evapotranspiration component as a probable driver of HM divergence in both summer and winter low flows. Moreover, the slope of the relationship between HM effects on summer low flows and HM effects on maxSWE in the Durance is quite consistent with findings from Godsey et al. (2014) on historical data in the Sierra Nevada (California). The less marked relationship obtained for the Verdon is again consistent with findings of Jenicek et al. (2016) who found a lower sensitivity of summer low flows to snow accumulation for less elevated catchments. Interpreting the positive (and significant) relation between HM effects on winter lows flows and HM effects on maxSWE is much more difficult. One would indeed expect on the contrary that storing less water in the snowpack would leave more water to sustain winter low flows. As mentioned above, winter low flows may originate from various and complex processes and some compensations may occur. Godsey et al. (2014) indeed found that under a changed climate, a reduction in maxSWE may be offset by increased storage in autumn or winter and by shifts in the timing of maximum evapotranspiration. Moreover, both Magand et al. (2014) and Lafaysse et al. (2014) showed that a reduction in snow cover area leads to a higher evaporation on the Durance catchment. Further studies aiming at explaining the precise processes leading to a divergence in HM responses on winter low flows should therefore explore these leads.

A way forward to disentangle the origins of the divergence in low-flow responses from different HMs in general would be to make use of the framework for understanding structural errors (FUSE, Clark et al., 2008), which has already been applied by Staudinger et al. (2011) to assess the performance on low-flow indicators of a variety of model structures. Assessing the robustness of such structures in a climate change context would perhaps lead to improvements of existing model structures as those used in the present work.

Finally, this study is based on the assumption that low-flow projections derived from all individual HMs - but also from all individual GCMs and SDMs - are equally valid. No simple relation could be found between present-day performance in simulating interannual variability in low-flow anomalies and HM effects. The robustness of the uncertainty decomposition results may therefore be tested with subsets of HMs, as well as subsets of GCMs and SDMs. It has to be noted that an experiment on HM uncertainty evolution following removal of an outlier model has been recently performed by Habets et al. (2013).

\subsection{Sources of uncertainty}

The hydrological projection data set explored in this work includes a fairly comprehensive list of uncertainty sources compared to most of previous studies (see Dobler et al., 2012; Addor et al., 2014, for recent hydrological studies with multiple uncertainty sources). The contribution of internal variability components is consistent with the analyses performed for the Durance by Hingray and Saïd (2014) on mean annual precipitation, and by Lafaysse et al. (2014) on mean annual streamflow.

The hierarchy of model uncertainties is, however, different from other hydrological indicators. For changes in the mean annual streamflow of the Durance catchment, SDM uncertainty was found to be larger than GCM uncertainty (Lafaysse et al., 2014). It is here much lower for low flows, probably due to the lower inter-SDM spread in dry/wet states than in precipitation amounts. However, one cannot exclude the possibility of the SDM contribution being underestimated, in two possible ways. First, one cannot guarantee that the sample of SDMs - but also GCMs and HMs - is representative from the unknown superpopulations. Indeed, no dynamical downscaling with a regional climate model has been, for example, considered here on top of the three SDMs. Moreover, the latter all belong to the single family of perfect prognosis methods (Maraun et al., 2010). Nevertheless, it has to be noted that the concepts for selecting analogue situations with the three SDMs used are quite different (see Sect. 2 and Lafaysse et al., 2014). Moreover, Lafaysse et al. (2014) found large differences between different versions of a given SDM using slightly different sets of predictors. It is therefore unclear whether more diverse SDMs - or a larger number of versions from the SDMs used - would contribute more to the total uncertainty. A second possible origin of the low SDM uncertainty contribution may be the shared adjustment of regional average temperature to the one of the driving GCM (see Sect. 2.2.2).

Additionally, some other potential sources of uncertainty were not considered. First, this data set is conditional on the single A1B emissions scenario, which should not be detrimental to results presented above given the relatively close time horizon considered. Adding the scenario uncertainty in the QE-ANOVA framework would be relatively straightforward, as it would take the form of an additional fixed effect alongside GCMs, SDMs, and HMs.

The uncertainty related to the temporal transferability of parameters - whether from SDMs or HMs - has not been considered either in this study. The hydrological uncertainty was found to be high when compared to that of SDMs and GCMs, but it was also likely underestimated. Indeed, the time transferability of HM parameters in a climate change context and its contribution to overall uncertainties has recently been explored by some studies (see e.g. Finger et al., 2012; Dobler et al., 2012; Parajka et al., 2016). One way to incorporate this source of uncertainty into the QE-ANOVA 
framework and combine it with HM structure uncertainty would be to devise a calibration protocol common to all HMs that would split the calibration period into distinct subperiods showing climatic contrasts, as proposed and applied by Thirel et al. (2015). Such a protocol has actually already been applied in the R2D2-2050 project (see Sauquet et al., 2014, p. 70-72) for a subset of HM structures and results show that all calibrated models seem equally robust with regard to their low-flow simulations. This will be the subject of a follow-up paper. When moving to future conditions, results based on CLSM for a small upstream Durance subcatchment showed that hydrological projections may be highly sensitive to the calibration period through some specific parameterized processes (Magand et al., 2015). Using such a calibration protocol may then allow computing the HM parameter contribution in a way similar to internal climate variability components in the QE-ANOVA framework.

\section{Conclusions}

This paper proposes a methodology for estimating the transient probability distribution of yearly hydrological variables conditional to an ensemble of projections built from multiple GCMs, multiple SDMs, and multiple HMs. The methodology is based on the QE-ANOVA framework that allows quantifying the contributions of the different sources of total uncertainty, by critically taking account of (1) large-scale internal variability stemming from the transient evolution of multiple GCM runs, and (2) small-scale internal variability derived from multiple realizations of stochastic SDMs. This framework thus allows deriving a hierarchy of climate and hydrological uncertainties that depends on the time horizon considered. It was initially developed for long-term climate averages and is here extended to include year-to-year climate variability in probabilistic hydrological projections, thereby following the recommendations of Sexton and Harris (2015). Indeed, results from climate impact and adaptation projects usually focus on time-slice changes, and therefore underestimate the role of climate variability. Taking the year-to-year variability - which is large for hydrological variables in general and for low flows in particular - into account is therefore especially relevant for better informing water resource adaptation strategies. To the authors' knowledge, it is the first time that a transient quantification of low-flow uncertainties (including internal variability) is proposed.
The QE-ANOVA framework is applied to better understand possible transient futures of both winter and summer low flows for two snow-influenced catchments in the southern French Alps. The analysis takes advantage of a very large data set of daily transient hydrological projections over the 1981-2065 period that combines in a comprehensive way 11 runs from four different GCMs, three SDMs with 10 stochastic realizations each, as well as six diverse HMs. Results from the extended QE-ANOVA approach may be summarized into three points. First, the change signal is a decrease in yearly low flows of around $-20 \%$ in 2065 with respect to the 19802009 reference, except for the most elevated catchment in winter where low flows barely decrease. Second, this change signal of yearly low-flow anomalies is largely masked by both large- and small-scale internal variability, even in 2065 at the end of the period considered. The time of emergence of the change signal on 30-year low-flow averages is, however, around 2035 , i.e. for time slices starting in 2020. Third, a large part of the total uncertainty - up to $40 \%$ in 2065 for 30year averages compared to less than $25 \%$ due to the GCMs - stems from the difference in HM responses.

Two main conclusions can be drawn from the above analysis, leading to corresponding lessons for future actions. First, internal variability brings by far the largest part of the uncertainty in low flows for an individual year in the future, even when the change signal is relatively large. Increasing the robustness and resilience of water systems to future climate conditions urges therefore water resources managers to first account for the internal climate variability. The scientific focus should then be on providing robust estimates of this variability by, for example, looking more and further into the past to identify benchmark situations and events that would serve as training sets for testing adaptation strategies, e.g. through historical hydrometeorological reconstructions (see e.g. Caillouet et al., 2016).

Second, low-flow responses from different HMs diverge in a changing climate, presumably due to differences in both evapotranspiration and snowpack components resulting from the large range of approaches implemented in the six models used here. HMs should therefore be carefully checked for their robustness in a changed climate in order to increase the confidence in hydrological projections. In particular, efforts should made for validating the robustness of all components of HMs with specific analyses and relevant data sets, notably for evapotranspiration and snowpack evolution. 


\section{Appendix A: Expressions of internal variability components}

\section{A1 Small-scale internal variability}

When a single GCM run is available for a given modelling chain $m$, the small-scale internal variability component of the relative change $\Delta$ for $m$ (see Eq. 2) can be estimated for any future prediction lead time $t$ from the empirical interrealization variance of $\Delta$ for $t$ (Eq. B2 in Hingray and Saïd, 2014). In the present work, the reference used for the estimation of the change variable is a constant (namely $\left.Y_{0}(m)\right)$. The expression thus simplifies as

$\operatorname{Var}_{k}(\Delta) \approx\left(\frac{\hat{y}(m, t)}{Y_{0}(m)}\right)^{2} \cdot \operatorname{Var}_{k}\left[\frac{Y(m, r, k, t)}{\hat{y}(m, t)}\right]$,

where $\operatorname{Var}_{k}$ is the empirical variance over stochastic realizations, $Y$ the relative change of the variable studied, $\hat{y}$ the trend model output, $r$ a GCM run, and $k$ a stochastic realization of the SDM from the model chain $m$ (see Sect. 3.2).

The variance in Eq. (A1) is equivalent to a coefficient of variation of $Y$ with respect to the inter-realization variance. Assuming this coefficient of variation as roughly constant over the whole simulation period, the SSIV of chain $m$ may be thus estimated from the temporal mean of this coefficient for this specific chain. When multiple runs are available for $m$, the SSIV of $\Delta$ for $m$ is estimated from the multirun mean of their temporal mean. The SSIV component for the whole projection ensemble is finally derived for each lead time $t$ as the multichain mean of these chain-specific estimates:

$$
\begin{aligned}
\operatorname{SSIV}(t) \approx & \frac{1}{N_{g} N_{s} N_{h}} \sum_{g=1}^{N_{g}} \sum_{s=1}^{N_{s}} \sum_{h=1}^{N_{h}} \frac{1}{T N_{g, r}}\left(\frac{\hat{y}(m, t)}{Y_{0}(m)}\right)^{2} \\
& \cdot \sum_{r=1}^{N_{g, r}} \sum_{t=1}^{T} \operatorname{Var}_{k}\left[\frac{Y(m, r, k, t)}{\hat{y}(m, t)}\right],
\end{aligned}
$$

where $T$ is the total number of time steps covered by the simulation period and $N_{g, r}$ is the number of runs for GCM $g$. Note that the SSIV is a function of time via the signal terms $\hat{y}(m, t)$ in Eqs. (A1) and (A2).

\section{A2 Large-scale internal variability}

The large-scale internal variability component for any given chain $m$ has the same expression as that of SSIV in Eq. (A1) but, due to the limited number of runs available, the inter-run variance (or equivalently the coefficient of variation) cannot be estimated in a robust way. Following the quasi-ergodic assumption for transient climate projections, the LSIV for $Y$ with respect to the inter-run dispersion is assumed to be, in terms of coefficient of variation, constant over the whole simulation period. It follows that for any time $t$ and any chain $m$ :

$\operatorname{Var}_{r}\left(\frac{Y(m, r, \bullet, t)}{\hat{y}(m, t)}\right) \approx \operatorname{Var}_{T}\left(\frac{Y(m, r, \bullet, t)}{\hat{y}(m, t)}\right)$. where $\operatorname{Var}_{r}$ is the empirical variance over runs, $\operatorname{Var}_{T}$ is the empirical variance over time, and $Y(m, r, \bullet, t)$ denotes the average over all stochastic realizations from SDM $s$.

When multiple runs are available for a chain, this variance component is estimated from all runs. The LSIV component of $\Delta$ is finally estimated from the multimodel mean of the temporal and inter-run variance of $Y(m, r, \bullet, t)$ (Eq. B6 in Hingray and Saïd, 2014). Again, as the reference used here for estimating relative changes is a constant, the expression simplifies as

$$
\begin{aligned}
\operatorname{LSIV}(t)= & \frac{1}{N_{g} N_{S} N_{h}} \sum_{g=1}^{N_{g}} \sum_{s=1}^{N_{s}} \sum_{h=1}^{N_{h}}\left(\frac{\hat{y}(m, t)}{Y_{0}(m)}\right)^{2} \\
& \cdot \operatorname{Var}_{T, N_{g, r}}\left(\frac{Y(m, r, \bullet, t)}{\hat{y}(m, t)}\right) .
\end{aligned}
$$

\section{Appendix B: Transferring normal distribution parameters to lognormal distribution parameters}

Let $m_{n}$ and $v_{n}$ be the mean and variance of a normal distribution. Let $M_{l}$ and $V_{l}$ be the mean and variance from the corresponding lognormal distribution. $M_{l}$ and $V_{l}$ can be expressed as

$$
\begin{aligned}
& M_{l}=e^{\left(m_{n}+\frac{v_{n}}{2}\right)} \\
& V_{l}=\left(e^{\left(v_{n}\right)}-1\right) \cdot e^{\left(2 \cdot m_{n}+v_{n}\right)} .
\end{aligned}
$$

This formulation is used in Sect. 3.3.3 to derive the distribution - and associated confidence bounds - of yearly low-flow indicators based on the grand ensemble $\mu$ and the total variance obtained from the QE-ANOVA decomposition. 
Author contributions. All authors collectively designed the experiments. Benoît Hingray and Jean-Philippe Vidal developed the model code and Jean-Philippe Vidal performed the simulations. Jean-Philippe Vidal prepared the manuscript with contributions from all co-authors.

Acknowledgements. This work was supported by funding from the French department in charge of the environment through the R2D2-2050 project. Analyses were performed in R (R Development Core Team, 2016), with packages lfstat (Koffler and Lahaa, 2014), tidyr (Wickham, 2014a, b), dplyr (Wickham and François, 2015), ggplot2 (Wickham, 2009, 2011), RColorBrewer (Neuwirth, 2014), RcppRoll (Ushey, 2015), and fitdistrplus (Delignette-Muller and Dutang, 2015). All authors thank participants from various partner institutions in the R2D2-2050 project that contributed their modelling outputs to the hydrological projection data set used here: Céline Monteil (EDF R\&D), Frédéric Hendrickx (EDF R\&D), Marie Bourqui (now at EDF DTG), Thibault Mathevet (EDF DTG), Matthieu Le Lay (EDF DTG), Joël Gailhard (EDF DTG), Matthieu Lafaysse (now at CNRM-CEN), Abdelkader Mezghani (now at Met.No), Flora Branger (Irstea HHLY), Fraņcois Tilmant (Irstea HHLY), Guillaume Thirel (Irstea HBAN), and Charles Perrin (Irstea HBAN). The authors would also like to thank Météo-France and EDF for providing access to the Safran and SPAZM databases, respectively. Finally, the authors would also like to thank the two anonymous referees and the editor (Kerstin Stahl) for detailed and quite relevant comments that greatly helped to improve the manuscript.

Edited by: Kerstin Stahl

Reviewed by: two anonymous referees

\section{References}

Addor, N., Rössler, O., Köplin, N., Huss, M., Weingartner, R., and Seibert, J.: Robust changes and sources of uncertainty in the projected hydrological regimes of Swiss catchments, Water Resour. Res., 50, 7541-7562, doi:10.1002/2014WR015549, 2014.

Allen, R. G., Pereira, L. S., Raes, D., and Smith, M.: Crop Evapotranspiration - Guidelines for computing crop water requirements, FAO Irrigation and Drainage Paper 56, FAO, 1998.

Barria, P., Walsh, K. J. E., Peel, M. C., and Karoly, D.: Uncertainties in runoff projections in southwestern Australian catchments using a global climate model with perturbed physics, J. Hydrol., 529, 184-199, doi:10.1016/j.jhydrol.2015.07.040, 2015.

Boé, J., Terray, L., Habets, F., and Martin, E.: A simple statistical-dynamical downscaling scheme based on weather types and conditional resampling, J. Geophys. Res., 111, D23106, doi:10.1029/2005JD006889, 2006.

Boé, J., Terray, L., Martin, E., and Habets, F.: Projected changes in components of the hydrological cycle in French river basins during the 21st century, Water Resour. Res., 45, W08426, doi:10.1029/2008WR007437, 2009.

Bosshard, T., Carambia, M., Goergen, K., Kotlarski, S., Krahe, P., Zappa, M., and Schär, C.: Quantifying uncertainty sources in an ensemble of hydrological climate-impact projections, Water Resour. Res., 49, 1523-1536, doi:10.1029/2011WR011533, 2013.

Bourqui, M., Mathevet, T., Gailhard, J., and Hendrickx, F.: Hydrological validation of statistical downscaling methods applied to climate model projections, in: Hydro-climatology: Variability and Change, edited by: Franks, S. W., Boegh, E., Blyth, E., Hannah, D. M., and Yilmaz, K. K., vol. 344 of IAHS-AISH Red Books/, 33-38, AISH, 2011.

Bracegirdle, T. J., Turner, J., Hosking, J. S., and Phillips, T.: Sources of uncertainty in projections of twenty-first century westerly wind changes over the Amundsen Sea, West Antarctica, in CMIP5 climate models, Clim. Dynam., 43, 2093-2104, doi:10.1007/s00382-013-2032-1, 2014.

Bréthaut, C. and Hill Clarvis, M.: Interdisciplinary approaches for analysing governance challenges across the Rhône basin, Reg. Environ. Change, 15, 499-503, doi:10.1007/s10113-014-0747-0, 2015.

Caillouet, L., Vidal, J.-P., Sauquet, E., and Graff, B.: Probabilistic precipitation and temperature downscaling of the Twentieth Century Reanalysis over France, Clim. Past, 12, 635-662, doi:10.5194/cp-12-635-2016, 2016.

Charlton-Perez, A. J., Hawkins, E., Eyring, V., Cionni, I., Bodeker, G. E., Kinnison, D. E., Akiyoshi, H., Frith, S. M., Garcia, R., Gettelman, A., Lamarque, J. F., Nakamura, T., Pawson, S., Yamashita, Y., Bekki, S., Braesicke, P., Chipperfield, M. P., Dhomse, S., Marchand, M., Mancini, E., Morgenstern, O., Pitari, G., Plummer, D., Pyle, J. A., Rozanov, E., Scinocca, J., Shibata, K., Shepherd, T. G., Tian, W., and Waugh, D. W.: The potential to narrow uncertainty in projections of stratospheric ozone over the 21st century, Atmos. Chem. Phys., 10, 94739486, doi:10.5194/acp-10-9473-2010, 2010.

Chauveau, M., Chazot, S., Perrin, C., Bourgin, P.-Y., Sauquet, E., Vidal, J.-P., Rouchy, N., Martin, E., David, J., Norotte, T., Maugis, P., and de Lacaze, X.: What will be the impacts of climate change on surface hydrology in France by 2070?, Houille Blanche, 1-15, doi:10.1051/lhb/2013027, 2013.

Christierson, B. v., Vidal, J.-P., and Wade, S. D.: Using UKCP09 probabilistic climate information for UK water resource planning, J. Hydrol., 424-425, 48-67, doi:10.1016/j.jhydrol.2011.12.020, 2012.

Clark, M. P., Slater, A. G., Rupp, D. E., Woods, R. A., Vrugt, J. A., Gupta, H. V., Wagener, T., and Hay, L. E.: Framework for Understanding Structural Errors (FUSE): A modular framework to diagnose differences between hydrological models, Water Resour. Res., 44, W00B02, doi:10.1029/2007WR006735, 2008.

Clarvis, M. H., Fatichi, S., Allan, A., Fuhrer, J., Stoffel, M., Romerio, F., Gaudard, L., Burlando, P., Beniston, M., and Xoplaki, E. Toreti, A.: Governing and managing water resources under changing hydro-climatic contexts: The case of the upper Rhone basin, Environ. Sci. Policy, 43, 56-67, doi:10.1016/j.envsci.2013.11.005, 2014.

Delignette-Muller, M. L. and Dutang, C.: fitdistrplus: An R Package for Fitting Distributions, J. Stat. Softw., 64, 1-34, 2015.

Deser, C., Phillips, A., Bourdette, V., and Teng, H.: Uncertainty in climate change projections: the role of internal variability, Climate Dynam., 38, 527-546, doi:10.1007/s00382-010-0977-x, 2012.

Dobler, C., Hagemann, S., Wilby, R. L., and Stötter, J.: Quantifying different sources of uncertainty in hydrological projections 
in an Alpine watershed, Hydrol. Earth Syst. Sci., 16, 4343-4360, doi:10.5194/hess-16-4343-2012, 2012.

Ducharne, A., Koster, R. D., Suarez, M. J., Stieglitz, M., and Kumar, P.: A catchment-based approach to modeling land surface processes in a general circulation model 2. Parameter estimation and model demonstration, J. Geophys. Res., 105, 24823-24838, doi:10.1029/2000JD900328, 2000.

Etchevers, P., Golaz, C., Habets, F., and Noilhan, J.: Impact of a climate change on the Rhone river catchment hydrology, J. Geophys. Res., 107, ACL 6-1-ACL 6-18, doi:10.1029/2001JD000490, 2002.

Fatichi, S., Rimkus, S., Burlando, P., Bordoy, R., and Molnar, P.: High-resolution distributed analysis of climate and anthropogenic changes on the hydrology of an Alpine catchment, J. Hydrol., 525, 362-382, doi:10.1016/j.jhydrol.2015.03.036, 2015.

Finger, D., Heinrich, G., Gobiet, A., and Bauder, A.: Projections of future water resources and their uncertainty in a glacierized catchment in the Swiss Alps and the subsequent effects on hydropower production during the 21 st century, Water Resour. Res., 48, W02521, doi:10.1029/2011WR010733, 2012.

Garçon, R.: Overall rain-flow model for flood forecasting and pre-determination, Houille Blanche, 54, 88-95, doi:10.1051/lhb/1999088, 1999.

Gardent, M., Rabatel, A., Dedieu, J.-P., and Deline, P.: Multitemporal glacier inventory of the French Alps from the late 1960s to the late 2000s, Global Planet. Change, 120, 24-37, doi:10.1016/j.gloplacha.2014.05.004, 2014.

Gelfan, A., Semenov, V. A., Gusev, E., Motovilov, Y., Nasonova, O., Krylenko, I., and Kovalev, E.: Large-basin hydrological response to climate model outputs: uncertainty caused by internal atmospheric variability, Hydrol. Earth. Syst. Sci., 19, 2737-2754, doi:10.5194/hess-19-2737-2015, 2015.

Giorgi, F. and Bi, X.: Time of emergence (TOE) of GHG-forced precipitation change hot-spots, Geophys. Res. Lett., 36, L06709, doi:10.1029/2009GL037593, 2009.

Giuntoli, I., Vidal, J.-P., Prudhomme, C., and Hannah, D. M.: Future hydrological extremes: the uncertainty from multiple global climate and global hydrological models, Earth Syst. Dynam., 6, 267-285, doi:10.5194/esd-6-267-2015, 2015.

Godsey, S. E., Kirchner, J. W., and Tague, C. L.: Effects of changes in winter snowpacks on summer low flows: case studies in the Sierra Nevada, California, USA, Hydrol. Process., 28, 50485064, doi:10.1002/hyp.9943, 2014.

Gottardi, F., Obled, C., Gailhard, J., and Paquet, E.: Statistical reanalysis of precipitation fields based on ground network data and weather patterns: Application over French mountains, J. Hydrol., 432-433, 154-167, doi:10.1016/j.jhydrol.2012.02.014, 2012.

Green, M. and Weatherhead, E. K.: The application of probabilistic climate change projections: a comparison of methods of handling uncertainty applied to UK irrigation reservoir design, J. Water Clim. Chang., 5, 652-666, doi:10.2166/wcc.2014.125, 2014.

Gupta, H. V., Kling, H., Yilmaz, K. K., and Martinez, G. F.: Decomposition of the mean squared error and NSE performance criteria: Implications for improving hydrological modelling, J. Hydrol., 377, 90-91, doi:10.1016/j.jhydrol.2009.08.003, 2009.

Habets, F., Boé, J., Déqué, M., Ducharne, A., Gascoin, S., Hachour, A., Martin, E., Pagé, C., Sauquet, E., Terray, L., Thiéry, D., Oudin, L., and Viennot, P.: Impact of climate change on the hydrogeology of two basins in northern France, Clim. Change, 121, 771-785, doi:10.1007/s10584-013-0934-x, 2013.

Hagemann, S., Chen, C., Clark, D. B., Folwell, S., Gosling, S. N., Haddeland, I., Hanasaki, N., Heinke, J., Ludwig, F., Voss, F., and Wiltshire, A. J.: Climate change impact on available water resources obtained using multiple global climate and hydrology models, Earth Syst. Dynam., 4, 129-144, doi:10.5194/esd4-129-2013, 2013.

Hawkins, E. and Sutton, R.: The potential to narrow uncertainty in regional climate predictions, Bull. Amer. Meteor. Soc., 90, 10951107, doi:10.1175/2009BAMS2607.1, 2009.

Hawkins, E. and Sutton, R.: The potential to narrow uncertainty in projections of regional precipitation change, Clim. Dynam., 37, 407-418, doi:10.1007/s00382-010-0810-6, 2011.

Hawkins, E. and Sutton, R.: Time of emergence of climate signals, Geophys. Res. Lett., 39, L01702, doi:10.1029/2011GL050087, 2012.

Hawkins, E. and Sutton, R.: Connecting climate model projections of global temperature change with the real world, B. Am. Meteor. Soc., 97, 963-980, doi:10.1175/BAMS-D-14-00154.1, 2016.

Hendrickx, F.: Impact of climate change on the hydrology of the Rhône catchment, Hydroécologie Appliquée, 13, 77-100, doi:10.1051/hydro:2001007, 2001.

Hingray, B. and Saïd, M.: Partitioning internal variability and model uncertainty components in a multimodel multireplicate ensemble of climate projections, J. Climate, 27, 6779-6798, doi:10.1175/JCLI-D-13-00629.1, 2014.

Hingray, B., Hendrickx, F., Bourqui, M., Creutin, J.-D., François, B., Gailhard, J., Lafaysse, M., Lemoine, N., Mathevet, T., Mezghani, A., and Monteil, C.: RIWER2030. Climat Régionaux et Incertitudes, Ressource en Eau et Gestion associée de 1860 à 2100, final report, ANR, 2013.

Huebener, H., Cubasch, U., Langematz, U., Spangehl, T., Niehörster, F., Fast, I., and Kunze, M.: Ensemble climate simulations using a fully coupled ocean-troposphere-stratosphere general circulation model, Philos. T. Roy. Soc. A, 365, 2089-2101, doi:10.1098/rsta.2007.2078, 2007.

Jenicek, M., Seibert, J., Zappa, M., Staudinger, M., and Jonas, T.: Importance of maximum snow accumulation for summer low flows in humid catchments, Hydrol. Earth. Syst. Sci., 20, 859874, doi:10.5194/hess-20-859-2016, 2016.

Johns, T. C., Royer, J.-F., Höschel, I., Huebener, H., Roeckner, E., Manzini, E., May, W., Dufresne, J.-L., Otterå, O. H., van Vuuren, D. P., Salas y Melia, D., Giorgetta, M. A., Denvil, S., Yang, S., Fogli, P. G., Körper, J., Tjiputra, J. F., Stehfest, E., and Hewitt, C. D.: Climate change under aggressive mitigation: the ENSEMBLES multi-model experiment, Clim. Dynam., 37, 1975-2003, doi:10.1007/s00382-011-1005-5, 2011.

Kalnay, E., Kanamitsu, M., Kistler, R. W., C., Deaven, D., Gandin, L., Iredell, M., Saha, S., White, G., Woollen, J., Zhu, Y., Chelliah, M., Ebisuzaki, W., Higgins, W., Janoviak, J., Mo, K. C., Ropelewski, C., Wang, J., Leetmaa, A., Reynolds, R., Jenne, R., and Joseph, D.: The NCEP/NCAR 40-year Reanalysis Project, B. Am. Meteor. Soc., 77, 437-471, doi:10.1175/15200477(1996)077<0437:TNYRP>2.0.CO;2, 1996.

Knutti, R., Furrer, R., Tebaldi, C., Cermak, J., and Meehl, G. A.: Challenges in combining projections from multiple climate models, J. Climate, 23, 2739-2758, doi:10.1175/2009JCLI3361.1, 2010. 
Koffler, D. and Lahaa, G.: Ifstat: Calculation of Low Flow Statistics for daily stream flow data, R package version 0.6, 2014.

Köplin, N., Rößler, O., Schädler, B., and Weingartner, R.: Robust estimates of climate-induced hydrological change in a temperate mountainous region, Clim. Change, 122, 171-184, doi:10.1007/s10584-013-1015-x, 2014.

Krause, P.: Quantifying the impact of land use changes on the water balance of large catchments using the J2000 model, Phys. Chem. Earth, 27, 663-673, doi:10.1016/S1474-7065(02)00051-7, 2002.

Krinner, G., Viovy, N., de Noblet-Ducoudré, N., Ogée, J., Polcher, J., Friedlingstein, P., Ciais, P., Sitch, S., and Prentice, I. C.: A dynamic global vegetation model for studies of the coupled atmosphere-biosphere system, Global Biogeochem. Cy., 19, GB1015, doi:10.1029/2003GB002199, 2005.

Laaha, G. and Blöschl, G.: A comparison of low flow regionalisation methods-catchment grouping, J. Hydrol., 323, 193-214, doi:10.1016/j.jhydrol.2005.09.001, 2006a.

Laaha, G. and Blöschl, G.: Seasonality indices for regionalizing low flows, Hydrol. Process., 20, 3851-3878, doi:10.1002/hyp.6161, 2006b.

Laaha, G., Demuth, S., Hisdal, H., Kroll, C. N., van Lanen, H. A. J., Nester, T., Rogger, M., Sauquet, E., Tallaksen, L. M., Woods, R., and Young, A.: Prediction of low flows in ungauged basins, in: Runoff Prediction in Ungauged Basins - Synthesis across Processes, Places and Scales, edited by: Blöschl, G., Sivapalan, M., Wagener, T., Viglione, A., and Savenije, H., chap. 8, 163-188, Cambridge University Press, Cambridge, UK, 2013.

Lafaysse, M., Hingray, B., Etchevers, P., Martin, E., and Obled, C.: Influence of spatial discretization, underground water storage and glacier melt on a physically-based hydrological model of the Upper Durance River basin, J. Hydrol., 403, 116-129, doi:10.1016/j.jhydrol.2011.03.046, 2011.

Lafaysse, M., Hingray, B., Terray, L., Mezghani, A., and Gailhard, J.: Internal variability and model uncertainty components in future hydrometeorological projections: The Alpine Durance basin, Water Resour. Res., 50, 3317-3341, doi:10.1002/2013WR014897, 2014.

Lorenz, E. N.: Atmospheric predictability as revealed by naturally occurring analogues, J. Atmos. Sci., 26, 636-646, doi:10.1175/1520-0469(1969)26<636:APARBN>2.0.CO;2, 1969.

Magand, C., Ducharne, A., Le Moine, N., and Gascoin, S.: Introducing hysteresis in snow depletion curves to improve the water budget of a land surface model in an Alpine catchment, J. Hydrometeorol., 15, 631-649, doi:10.1175/JHM-D-13-091.1, 2014.

Magand, C., Ducharne, A., Le Moine, N., and Brigode, P.: Parameter transferability under changing climate: case study with a land surface model in the Durance watershed, France, Hydrol. Sci. J., 60, 1408-1423, doi:10.1080/02626667.2014.993643, 2015.

Maraun, D., Wetterhall, F., Ireson, A. M., Chandler, R. E., Kendon, E. J., Widmann, M., Brienen, S., Rust, H. W., Sauter, T., Themessl, M., Venema, V. K. C., Chun, K. P., Goodess, C. M., Jones, R. G., Onof, C., Vrac, M., and Thiele-Eich, I.: Precipitation downscaling under climate change. Recent developments to bridge the gap between dynamical models and the end user, Rev. Geophys., 48, RG3003, doi:10.1029/2009RG000314, 2010.

Marti, O., Braconnot, P., Dufresne, J.-L., Bellier, J., Benshila, R., Bony, S., Brockmann, P., Cadule, P., Caubel, A., Codron, F., de Noblet, N., Denvil, S., Fairhead, L., Fichefet, T., Foujols, M.-
A., Friedlingstein, P., Goosse, H., Grandpeix, J.-Y., Guilyardi, E., Hourdin, F., Idelkadi, A., Kageyama, M., Krinner, G., Lévy, C., Madec, G., Mignot, J., Musat, I., Swingedouw, D., and Talandier, C.: Key features of the IPSL ocean atmosphere model and its sensitivity to atmospheric resolution, Clim. Dynam., 34, 1-26, doi:10.1007/s00382-009-0640-6, 2010.

McKay, M. D., Beckman, R. J., and Conover, W. J.: A comparison of three methods for selecting values of input variables in the analysis of output from a computer code, Technometrics, 21, 239-245, doi:10.2307/1268522, 1979.

Mezghani, A. and Hingray, B.: A combined downscalingdisaggregation weather generator for stochastic generation of multisite hourly weather variables over complex terrain: Development and multi-scale validation for the Upper Rhone River basin, J. Hydrol., 377, 245-260, doi:10.1016/j.jhydrol.2009.08.033, 2009.

Minasny, B. and McBratney, A. B.: A conditioned Latin hypercube method for sampling in the presence of ancillary information, Comput. Geosci., 32, 1378-1388, doi:10.1016/j.cageo.2005.12.009, 2006.

Moatar, F., Ducharne, A., Thiéry, D., Bustillo, V., Sauquet, E., and Vidal, J.-P.: La Loire à l'épreuve du changement climatique, Géosciences, 12, 79-87, 2010.

Murphy, J. M., Sexton, D. M. H., Jenkins, G. J., Booth, B. B. B., Brown, C. C., Clark, R. T., Collins, M., Harris, G. R., Kendon, E. J., Betts, R. A., Brown, S. J., Humphrey, K. A., McCarthy, M. P., McDonald, R. E., Stephens, A., Wallace, C., Warren, R., Wilby, R., and Wood, R. A.: Climate change projections, UK climate projections science report, Met Office Hadley Centre, Exeter, 2009.

Nakićenović, N., Alcamo, J., Davis, G., de Vries, B., Fenhann, J., Gaffin, S., Gregory, K., Grübler, A., Jung, T. Y., Kram, T., La Rovere, E. L., Michaelis, L., Mori, S., Morita, T., Pepper, W., Pitcher, H., Price, L., Riahi, K., Roehrl, A., Rogner, H.-H., Sankovski, A., Schlesinger, M., Shukla, P., Smith, S., Swart, R., van Rooijen, S., Victor, N., and Dadi, Z.: Special Report on Emissions Scenarios, Cambridge University Press, 570 pp., 2000.

Neuwirth, E.: RColorBrewer: ColorBrewer Palettes, R package version 1.1-2, 2014.

Northrop, P. J. and Chandler, R. E.: Quantifying sources of uncertainty in projections of future climate, J. Climate, 27, 8793-8808, doi:10.1175/JCLI-D-14-00265.1, 2014.

Obled, C., Bontron, G., and Garçon, R.: Quantitative precipitation forecasts: a statistical adaptation of model outputs through an analogues sorting approach, Atmos. Res., 63, 303-324, doi:10.1016/S0169-8095(02)00038-8, 2002.

Paiva, R., Collischonn, W., Schnetterling, E. B., Vidal, J.-P., Hendrickx, F., and Lopez, A.: The Case Studies, in: Modelling the impact of climate change on water resources, edited by Fung, F., Lopez, A., and New, M., chap. 6, 136-182, John Wiley \& Sons, Ltd, Chichester, UK, doi:10.1002/9781444324921.ch6, 2010.

Parajka, J., Blaschke, A. P., Blöschl, G., Haslinger, K., Hepp, G., Laaha, G., Schöner, W., Trautvetter, H., Viglione, A., and Zessner, M.: Uncertainty contributions to low-flow projections in Austria, Hydrol. Earth. Syst. Sci., 20, 2085-2101, doi:10.5194/hess-20-2085-2016, 2016.

Peel, M. C., Srikanthan, R., McMahon, T. A., and Karoly, D. J.: Approximating uncertainty of annual runoff and reservoir yield using stochastic replicates of global climate model data, Hy- 
drol. Earth. Syst. Sci., 19, 1615-1639, doi:10.5194/hess-191615-2015, 2015.

Pushpalatha, R., Perrin, C., Le Moine, N., Mathevet, T., and Andréassian, V.: A downward structural sensitivity analysis of hydrological models to improve low-flow simulation, J. Hydrol., 411, 66-76, doi:10.1016/j.jhydrol.2011.09.034, 2011.

R Development Core Team: R: A Language and Environment for Statistical Computing, R Foundation for Statistical Computing, Vienna, Austria, 2016.

Raïsänen, J.: $\mathrm{CO}_{2}$-induced climate change in CMIP2 experiments: Quantification of agreement and role of internal variability, J. Climate, 14, 2088-2104, doi:10.1175/15200442(2001)014<2088:CICCIC>2.0.CO;2, 2001

Roeckner, E., Giorgetta, M. A., Crueger, T., Esch, M., and Pongratz, J.: Sensitivity of simulated climate to horizontal and vertical resolution in the ECHAM5 atmosphere model, J. Climate, 19, 3771-3791, doi:10.1175/JCLI3824.1, 2006.

Salas-Mélia, D., Chauvin, F., Déqué, M., Douville, H., Guérémy, J.F., Marquet, P., Planton, S., Royer, J.-F., and Tyteca, S.: Description and validation of the CNRM-CM3 global coupled model, CNRM Working Note 103, CNRM-GAME, 2005.

Sanderson, B. M. and Knutti, R.: On the interpretation of constrained climate model ensembles, Geophys. Res. Lett., 39, L16708, doi:10.1029/2012GL052665, 2012.

Sansom, P. G., Stephenson, D. B., Ferro, C. A. T., Zappa, G., and Shaffrey, L.: Simple uncertainty frameworks for selecting weighting schemes and interpreting multi-model ensemble climate change experiments, J. Climate, 26, 4017-4037, doi:10.1175/JCLI-D-12-00462.1, 2013.

Sauquet, E., Arama, Y., Blanc-Coutagne, E., Bouscasse, H., Branger, F., Braud, I., Brun, J.-F., Chrel, Y., Cipriani, T., Datry, T., Ducharne, A., Hendrickx, F., Hingray, B., Krowicki, F., Le Goff, I., Le Lay, M., Magand, C., Malerbe, F., Mathevet, T., Monteil, C., Perrin, C., Poulhe, P., Rossi, A., Samie, R., Strosser, P., Thirel, G., Tilmant, F., and Vidal, J.-P.: Risk, water Resources and sustainable Development within the Durance river basin in 2050, Final Report 10-GCMOT-GICC-3-CVS-102, MEDDE, 2014

Schewe, J., Heinke, J., Gerten, D., Haddeland, I., Arnell, N. W., Clark, D. B., Dankers, R., Eisner, S., Fekete, B. M., ColónGonzález, F. J., Gosling, S. N., Kim, H., Liu, X., Masaki, Y., Portmann, F. T., Satoh, Y., Stacke, T., Tang, Q., Wada, Y., Wisser, D., Albrecht, T., Frieler, K., Piontek, F., Warszawski, L., and Kabat, P.: Multimodel assessment of water scarcity under climate change, P. Natl. Acad. Sci. USA, 111, 3245-3250, doi:10.1073/pnas.1222460110, 2014.

Seiller, G. and Anctil, F.: Climate change impacts on the hydrologic regime of a Canadian river: comparing uncertainties arising from climate natural variability and lumped hydrological model structures, Hydrol. Earth. Syst. Sci., 18, 2033-2047, doi:10.5194/hess-18-2033-2014, 2014.

Sexton, D. M. H. and Harris, G. R.: The importance of including variability in climate change projections used for adaptation, Nature Clim. Change, 5, 931-936, doi:10.1038/nclimate2705, 2015.

Staudinger, M., Stahl, K., Seibert, J., Clark, M. P., and Tallaksen, L. M.: Comparison of hydrological model structures based on recession and low flow simulations, Hydrol. Earth. Syst. Sci., 15, 3447-3459, doi:10.5194/hess-15-3447-2011, 2011.
Thirel, G., Andréassian, V., Perrin, C., Audouy, J.-N., Berthet, L., Edwards, P., Folton, N., Furusho, C., Kuentz, A., Lerat, J., Lindström, G., Martin, E., Mathevet, T., Merz, R., Parajka, J., Ruelland, D., and Vaze, J.: Hydrology under change: an evaluation protocol to investigate how hydrological models deal with changing catchments, Hydrol. Sci. J., 60, 1184-1199, doi:10.1080/02626667.2014.967248, 2015.

Ushey, K.: RcppRoll: Efficient Rolling/Windowed Operations, r package version 0.2.2, 2015.

van der Linden, P. and Mitchell, J. F. B.: ENSEMBLES: Climate Change and its Impacts: Summary of research and results from the ENSEMBLES project, Tech. rep., Met Office Hadley Centre, 2009.

Van Loon, A. F., Van Lanen, H. A. J., Hisdal, H., Tallaksen, L. M., Fendeková, M., Oosterwijk, J., Horvát, O., and Machlica, A.: Understanding hydrological winter drought in Europe, in: Global Change: Facing Risks and Threats to Water Resources, edited by: Servat, E., Demuth, S., Dezetter, A., and Daniell, T., no. 340 in IAHS Red Books, 189-197, IAHS, 2010.

Van Loon, A. F., Ploum, S. W., Parajka, J., Fleig, A. K., Garnier, E., Laaha, G., and Van Lanen, H. A. J.: Hydrological drought types in cold climates: Quantitative analysis of causing factors and qualitative survey of impacts, Hydrol. Earth. Syst. Sci., 19, 1993-2016, doi:10.5194/hess-19-1993-2015, 2015.

van Pelt, S. C.and Beersma, J. J., Buishand, T. A., van den Hurk, B. J. J. M., and Schellekens, J.: Uncertainty in the future change of extreme precipitation over the Rhine basin: the role of internal climate variability, Clim. Dynam., 44, 1789-1800, doi:10.1007/s00382-014-2312-4, 2015.

Vetter, T., Huang, S., Aich, V., Yang, T., Wang, X., Krysanova, V., and Hattermann, F.: Multi-model climate impact assessment and intercomparison for three large-scale river basins on three continents, Earth Syst. Dynam., 6, 17-43, doi:10.5194/esd-6-17-2015, 2015.

Vidal, J.-P., Martin, E., Franchistéguy, L., Baillon, M., and Soubeyroux, J.-M.: A 50-year high-resolution atmospheric reanalysis over France with the Safran system, Int. J. Climatol., 30, 1627 1644, doi:10.1002/joc.2003, 2010.

Vidal, J.-P., Martin, E., Kitova, N., Najac, J., and Soubeyroux, J.M.: Evolution of spatio-temporal drought characteristics: validation, projections and effect of adaptation scenarios, Hydrol. Earth. Syst. Sci., 16, 2935-2955, doi:10.5194/hess-16-29352012, 2012.

von Storch, H. and Zwiers, F.: Statistical analysis in climate research, Cambridge University Press, Cambridge, 484 pp., 1999.

Warner, R. F.: Environmental flows in two highly regulated rivers: the Hawkesbury Nepean in Australia and the Durance in France, Water Environ. J., 28, 365-381, doi:10.1111/wej.12045, 2013.

Whitfield, P. H.: Is 'Centre of Volume' a robust indicator of changes in snowmelt timing?, Hydrol. Process., 27, 2691-2698, doi:10.1002/hyp.9817, 2013.

Wickham, H.: ggplot2: elegant graphics for data analysis, Use R!, Springer, New York, 221 pp., 2009.

Wickham, H.: ggplot2, WIREs Comput. Stat., 3, 180-185, doi:10.1002/wics.147, 2011.

Wickham, H.: Tidy data, J. Stat. Softw., 59, 1-23, 2014a.

Wickham, H.: tidyr: Easily Tidy Data with spread and gather Functions., R package version $0.2 .0,2014 \mathrm{~b}$. 
Wickham, H. and François, R.: dplyr: A Grammar of Data Manipulation, $\mathrm{R}$ package version 0.4.1, 2015.

Wilby, R. L. and Dessai, S.: Robust adaptation to climate change, Weather, 65, 180-185, doi:10.1002/wea.543, 2010.

Wilby, R. L. and Harris, I.: A framework for assessing uncertainties in climate change impacts: Low-flow scenarios for the River Thames, UK, Water Resour. Res., 42, W02419, doi:10.1029/2005WR004065, 2006.
WMO: Manual on low-flow estimation and prediction, Operational Hydrology Report 30, WMO-no. 1029, WMO, Geneva, Switzerland, 2008.

Yip, S., Ferro, C. A. T., and Stephenson, D. B.: A simple, coherent framework for partitioning uncertainty in climate predictions, $\mathrm{J}$. Climate, 24, 4634-4643, doi:10.1175/2011JCLI4085.1, 2011. 